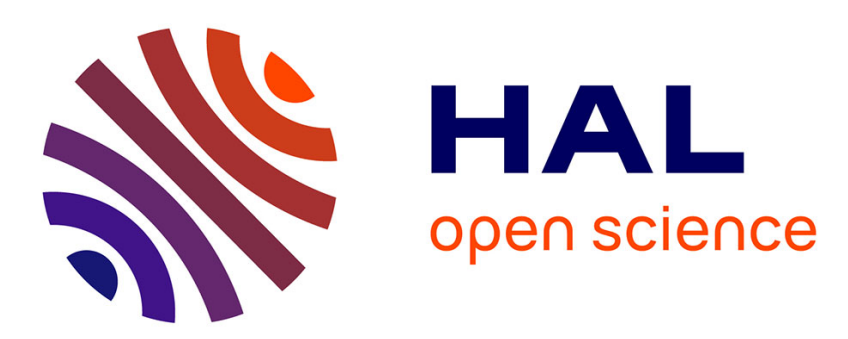

\title{
Simulations of the thermo-hydro-mechanical behaviour of an annular reinforced concrete structure heated up to $200^{\circ} \mathrm{C}$
}

Benoît Bary, Marcus V G de Morais, Stéphane Poyet, Sabine Durand

\section{- To cite this version:}

Benoît Bary, Marcus V G de Morais, Stéphane Poyet, Sabine Durand. Simulations of the thermohydro-mechanical behaviour of an annular reinforced concrete structure heated up to $200^{\circ} \mathrm{C}$. Engineering Structures, 2012, 36, pp.302 - 315. 10.1016/j.engstruct.2011.12.007 . cea-03293563

\section{HAL Id: cea-03293563 \\ https://hal-cea.archives-ouvertes.fr/cea-03293563}

Submitted on 21 Jul 2021

HAL is a multi-disciplinary open access archive for the deposit and dissemination of scientific research documents, whether they are published or not. The documents may come from teaching and research institutions in France or abroad, or from public or private research centers.
L'archive ouverte pluridisciplinaire HAL, est destinée au dépôt et à la diffusion de documents scientifiques de niveau recherche, publiés ou non, émanant des établissements d'enseignement et de recherche français ou étrangers, des laboratoires publics ou privés. 


\title{
Simulations of the thermo-hydro-mechanical behaviour of an annular reinforced concrete structure heated up to $200^{\circ} \mathrm{C}$
}

\author{
Benoît Bary ${ }^{\mathrm{a}, *}$, Marcus V.G. de Morais ${ }^{\mathrm{a}}$, Stéphane Poyet ${ }^{\mathrm{a}}$, Sabine Durand ${ }^{\mathrm{b}}$ \\ ${ }^{a}$ CEA, DEN, DPC, SCCME, Laboratoire d'Etude du Comportement des Bétons et des Argiles, F-91191 Gif-sur-Yvette, France \\ ${ }^{\mathrm{b}}$ CEA, DEN, DM2S, SEMT, Laboratoire de Mécanique Systèmes et Simulation, F-91191 Gif-sur-Yvette, France
}

\section{A R T I C L E I N F O}

\section{Article history:}

Received 2 May 2011

Revised 29 November 2011

Accepted 2 December 2011

\section{Keywords:}

Thermo-hydro-mechanical coupling

Numerical simulations

Reinforced concrete

Temperature-dependent sorption curves Damage

\begin{abstract}
A B S T R A C T
We analyze in this study the numerical thermo-hydro-mechanical response of an annular reinforced concrete structure called MAQBETH subjected to a thermal loading up to $200^{\circ} \mathrm{C}$ during more than $250 \mathrm{~h}$. This mock-up is typical of concrete structures in nuclear waste storage conditions under accidental situations. The simulations are performed with a simplified coupled model based on the mechanics of partially saturated porous media, which was previously developed in [1]. As a main contribution of this paper, we explicitly take into account the temperature effects in the water retention curves, via the introduction of the isosteric heat of sorption. These effects result in a significant reduction of the saturation degree at any given relative humidity for increasing temperatures. The numerical results of the MAQBETH simulation are then compared with experimental ones in terms of profiles of temperature, relative humidity, gas pressures and strains in the median plan at different times. This comparison shows a reasonable agreement. The effects of the temperature-dependent sorption curves are further analyzed through additional simulations carried out with a constant sorption curve. Large differences in the relative humidity and saturation degree profiles, and to a lesser extent in the gas pressure profiles, are observed between the two cases.
\end{abstract}

(c) 2011 Elsevier Ltd. All rights reserved.

\section{Introduction}

The precise characterization of the mid and long-term behaviour of concrete is of paramount importance in the context of nuclear plant containments and radioactive waste management. For the latter case, cementitious materials are considered as an attractive option for building structures. These constructions are typically subjected in service to combined moderate thermal (less than $100^{\circ} \mathrm{C}$ ) and mechanical loadings, but may experience temporary accidental situations characterized by temperature increase up to $200^{\circ} \mathrm{C}$. In general, thermal loadings accelerate the moisture transfers by increasing the related gradients between the material and the environment. Moreover, the thermomechanical loadings may cause more or less severe cracking, leading in turn to locally augment the transport properties and then to lessen the radionuclide confinement function of the structure, which is critical in the framework of nuclear waste storage.

The precise description of short as well as long-term behaviour of deformable porous media subjected to thermal loadings is generally achieved by means of coupled models involving heat conduction, liquid and gaseous water flow, and interactions of these fluid

\footnotetext{
* Corresponding author. Tel.: +33 1690823 83; fax: +3316908 8441 .

E-mail address: benoit.bary@cea.fr (B. Bary).
}

phases with the solid skeleton (see e.g. [2-4]). The corresponding models are then constituted by several non-linear coupled differential equations describing many physical phenomena, with a large amount of parameters to identify. The more sophisticated formulations involve three interacting fluid phases: dry air, vapour water and liquid (see e.g. [3-8]). Numerous comparisons to experimental data have confirmed the interest of these numerical developments for the simulation of the thermo-hydro-mechanical (THM) concrete structure response. In particular, they allow predicting both hydric state and temperature evolutions within the structure, which are of great importance when reactive porous materials like concrete are considered. Indeed, this material may be subjected to the penetration of aggressive substances from the environment (chlorides, carbon dioxide...), and the transport properties of these substances as well as the induced chemical reactions are significantly affected by both the local internal saturation state and the temperature. Moreover, differed deformations due to shrinkage and creep phenomena, which may in the long term provoke more or less severe cracking, are known to be deeply related to these two factors (see e.g. [9]). Then, the precise knowledge of the thermo-hydric state of concrete structures is not only important with regards to their mechanical response, but also concerning the long-term material durability.

We focus in this work on the THM behaviour of concrete structures subjected to temperatures up to $200^{\circ} \mathrm{C}$, as may be encountered in accidental situations in the context of nuclear waste 
storage. More precisely, we investigate and analyze the numerical THM response of a large reinforced concrete structure called MAQBETH and representing a prototype of a ring enclosing nuclear wastes in a typical waste disposal concept. This structure is constituted of a hollow cylinder with external diameter of $2.2 \mathrm{~m}$ and height of $3 \mathrm{~m}$, and it has undergone a thermal loading at $200{ }^{\circ} \mathrm{C}$ during several hundreds of hours. To describe the macroscopic THM behaviour of concrete, a simplified coupled model (denoted as THMs in the following) was developed at CEA/LECBA in the last few years. This THMs model is based on the mechanics of partially saturated porous media and assumes that the gaseous phase is composed exclusively of vapour [1]. This hypothesis leads to substantial simplification in the theoretical formulation since only one equation governs the mass conservation of the water in both liquid and gas form. The THMs model was applied to the simulation of plain concrete structures in [1], and in this study it is then applied to the simulation of the reinforced concrete structure MAQBETH. Its capacity to reproduce the main features of the concrete structure including the reinforcement rebars will be evaluated through the comparison between numerical and experimental results in terms of evolution of temperatures, gas pressures, relative humidity and strains in the median plan of the structure as a function of time.

As a second objective of this study, the modelling of the sorption curves is improved so as to take into account the effects of the temperature through the introduction of the isosteric heat of sorption. Such effects are indeed known to be of significant influence on these curves, and then on the hydric state (e.g. [10,11]). The numerical implementation into the THM model of the corresponding formulation is further described and some simplifications are proposed and discussed. This temperature-dependence is in general not considered in most existing models for simplicity, and also due to the lack of available experimental data. Their consequences on the concrete structure response and in particular on the temporal evolutions of the hydric state are next analyzed through a detailed comparison of the numerical results obtained with non-evolving and with temperature-dependent sorption curves. Specifically, the simulations results are studied in terms of relative humidity, saturation degree and gas pressures profiles at different times.

The paper is organized as follows. The reinforced concrete structure is briefly described in Section 2 . The coupled THM model used for the simulations is recalled in Section 3, with a particular focus on the temperature-dependent sorption curves modelling. The Section 4 presents and analyses the numerical results obtained, and confronts them to experimental data. Finally, some concluding remarks and perspectives are given in Section 5.

\section{Description of the MAQBETH mock-up}

The MAQBETH mock-up is a large scale experiment developed at the French Atomic Energy Commission (CEA Saclay), in order to get exploitable experimental data on concrete structures subjected to loadings representative of those encountered in the context of nuclear interim waste storage structures, and then to support their conception [12]. The design of this mock-up was guided mainly by specific characteristics and loading conditions of this type of structures (high performance concrete, large thickness for radioprotection, slow heating rates, and moderate to high temperature levels maintained for long periods). The main objective of this study was to provide a series of temporal data regarding the THM behaviour of a large scale experiment. To this aim, several sensors are radially placed inside the structure to measure the temporal evolutions of temperature, gas pressure and relative humidity. Strain gauges are further set on the inner surface at mid-height to measure both vertical and orhoradial strains.

The MAQBETH mock-up is a reinforced hollow concrete cylinder with an inner and outer diameter of 1 and $2.2 \mathrm{~m}$, respectively, and a height of $3 \mathrm{~m}$ (see Figs. 1 and 2). The dimensioning criteria adopted limit the steel stress to a maximum of $300 \mathrm{MPa}$ (corresponding to a crack opening of $0.3 \mathrm{~mm}$ ) with a concrete compressive stress smaller than $30 \mathrm{MPa}$ at the heated surface. Following these criteria, the steel reinforcement is concentrated near the surfaces, leaving a central zone to experimental measures. The total weight of reinforcement rebars corresponds to $10 \%$ of the mockup weight ( 2.2 tons). The steel reinforcements are composed of high quality steel of high adherence (CRELOI 500S) with a diameter of 25 and $16 \mathrm{~mm}$ for the vertical rebars in the inner part of the structure. The mock-up is laid on a $60 \mathrm{~mm}$ thick wooden plate and its top is covered with a $200 \mathrm{~mm}$ thick insulator layer and a $30 \mathrm{~mm}$ thick wooden layer [13].

The hollow cylinder geometry for the reinforced concrete structure is representative of real nuclear storage structures; its dimensions result from the following constraints:

- having a sufficient thickness to obtain high temperature gradients, to limit the scale effects and to be representative of real civil engineering structures,

- radial symmetries allowing the installation of several sensors, possibly of important size,

- obtaining one-dimensional moisture and heat flows,

- considering a zone in the structure at mid-height where the influence of boundary effects is negligible (in terms of temperature loading as well as hydrous and mechanical ones), thus
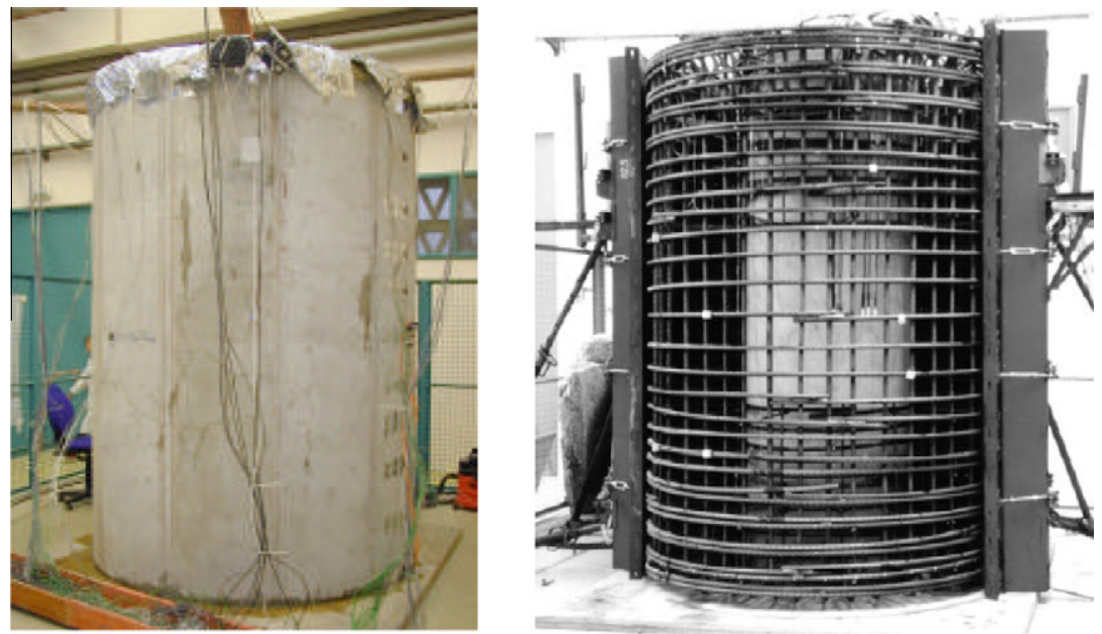

Fig. 1. General view of MAQBETH mock-up (left) and cylindrical steel reinforcement (right) [12]. 

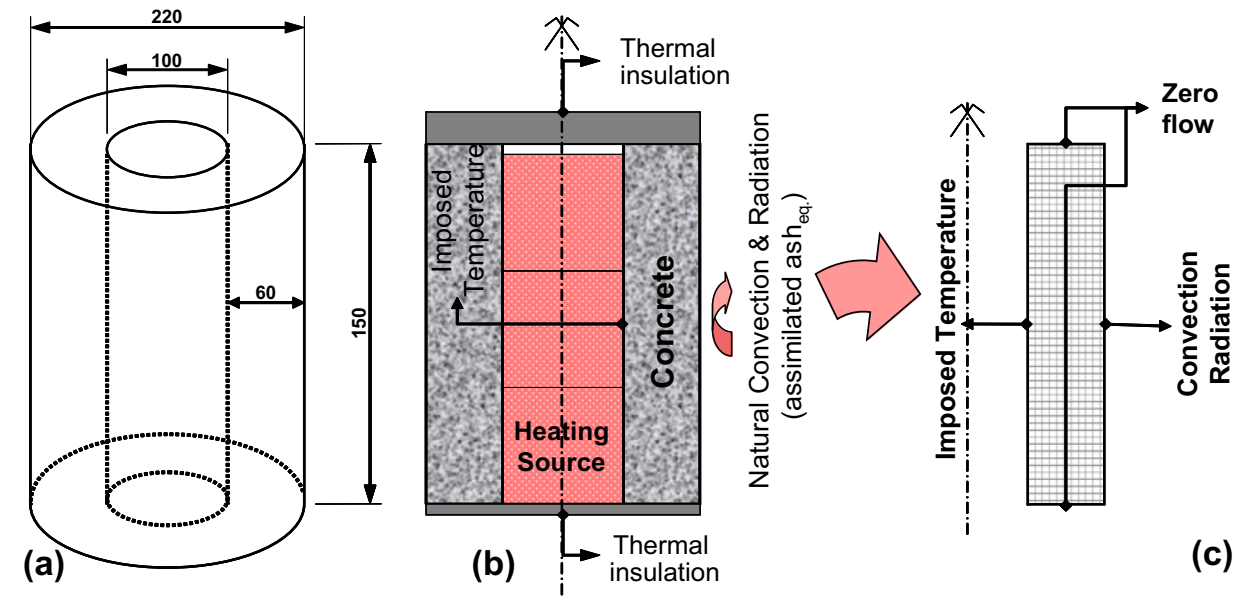

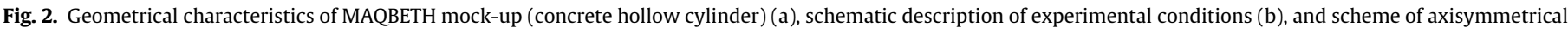
numerical model (c).

Table 1

Experimental concrete composition of MAQBETH mock-up.

\begin{tabular}{ll}
\hline Data & Value \\
\hline Cement mass $m_{\mathrm{c}}$ (CEM I 52,5 Lafarge) & $354 \mathrm{~kg} / \mathrm{m}^{3}$ \\
Aggregate mass $m_{\mathrm{a}}$ & $1877 \mathrm{~kg} / \mathrm{m}^{3}$ \\
Calcium-siliceous gravel 5-20 mm & $715 \mathrm{~kg} / \mathrm{m}^{3}$ \\
Fine calcium-siliceous gravel 5-14 mm & $402 \mathrm{~kg} / \mathrm{m}^{3}$ \\
Siliceous sand 0-5 mm & $760 \mathrm{~kg} / \mathrm{m}^{3}$ \\
Mix water $m_{\mathrm{w}}$ & $154 \mathrm{~kg} / \mathrm{m}^{3}$ \\
Superplasticizer optima 100 & $5.31 \mathrm{~kg} / \mathrm{m}^{3}$ \\
Water/cement ratio & 0.43 \\
Hydrated water $d_{\mathrm{o}}$ & $0.9 \times 0.21 \times m_{\mathrm{c}}$
\end{tabular}

allowing to concentrate the instrumentation in a quasi-homogeneous behaviour zone.

The cylindrical geometry also allowed the installation of very simple heating system composed of three heating-mandrills of approximately $10 \mathrm{~kW}$ each and an external diameter $(0.98 \mathrm{~m})$ slightly lower than internal diameter of the mock-up.

The concrete composition and characteristics are listed in Table 1. Concrete was prepared using a standard Portland cement [12]. This composition was adapted to optimize the solid skeleton and to follow the usual criteria of durability (low water/cement ratio, high cement content...) for current concrete structures. Its mechanical characteristics (compressive strength at 28 days over $60 \mathrm{MPa}$ ) and its reduced permeability allow the classification of high performance concrete (HPC).

\section{THM governing equations}

In this section the behaviour of both concrete and steel materials are first recalled and specified in the particular conditions of moderate thermomechanical loadings. The model proposed for taking into account the effects of the temperature on the sorption curves is then presented and discussed in the second subsection.

\subsection{Description of the THMs model}

This subsection is largely devoted to the governing equations of the simplified THM model developed in [1], which are briefly recalled hereafter. We focus our attention on the concrete behaviour since this material constitutes the major part of the MAQBETH structure, and is furthermore particularly affected by the thermo- hydric $(\mathrm{TH})$ evolutions and by cracking resulting from $\mathrm{TH}$ as well as mechanical loadings. On the other hand, reinforcement rebars act essentially on the mechanical response of the whole structure: steel is indeed assumed unchanged by the hydric state of the surrounding material for the typical simulation times considered in this study, and the results have further shown that the effects of the presence of the reinforcement bars on the temperature evolutions are negligible.

In the THMs formulation, it is assumed that the gas phase is constituted only of water vapour, i.e. the dry air is neglected. This hypothesis allows combining both mass conservation equations of water (liquid and vapour) into a single one. Cracking is simply described in the model via an isotropic damage variable related to randomly distributed microcracks represented as penny-shaped ellipsoids. In [1] the model was applied to the simulation of a plain concrete cylinder of $0.80 \mathrm{~m}$ height and $0.80 \mathrm{~m}$ diameter subjected to heating up to $160{ }^{\circ} \mathrm{C}$. The numerical results were proven to correctly reproduce the experimental data in terms of temperature and pore pressure evolutions within the structure, including in the transient regime. Subsequently, the simplified model was confronted in [14] to a more sophisticated model in which the dry air was no more neglected and considered as a constituent of the problem, thus leading to a supplementary mass conservation equation in the system. The two models were applied to the simulation of a $16 \times 32 \mathrm{~cm}$ cylindrical concrete specimen heated up to $200{ }^{\circ} \mathrm{C}$. Very comparable results were obtained, which were furthermore in good agreement with experimental data, thus justifying the use of the simplified model in the corresponding range of temperature and loading conditions.

\subsubsection{Mechanical behaviour}

The classical Biot formulation extended to the unsaturated case is retained for expressing the concrete mechanical behaviour (see e.g. $[2,4,15])$, assumed to be isotropic. The stress tensor $\boldsymbol{\sigma}$ takes the form:

$\boldsymbol{\sigma}=2 \mu \mathbf{J}: \boldsymbol{\varepsilon}+3 k \boldsymbol{L}: \boldsymbol{\varepsilon}-b \mathbf{I} p_{l}-3 \alpha k \theta \mathbf{I}$

where $\boldsymbol{\varepsilon}$ is the strain tensor, $\boldsymbol{L}$ and $\boldsymbol{J}$ are projection operators such that $\boldsymbol{L}=\frac{1}{3} \boldsymbol{I} \otimes \boldsymbol{I}$ and $\boldsymbol{J}=\boldsymbol{I} \otimes \boldsymbol{I}-\boldsymbol{L}$ with $\boldsymbol{I}$ the second order identity tensor, $\mu$ and $k$ the shear and bulk moduli in isothermal drained conditions, $b$ the Biot coefficient, $p_{l}$ the liquid pressure, $\alpha$ the coefficient of thermal expansion, and $\theta=T-T_{0}$ with $T$ and $T_{0}$ the current and initial temperatures, respectively. The Eq. (1) is formulated with the assumptions that only infinitesimal transformations are considered, and that the mechanical effects of the gaseous phase on the solid 
skeleton are negligible relative to the ones of the liquid phase (see $[1,16]$ for further details). It should be noted that the latter hypothesis appears reasonable for slow heating rates and moderate temperatures as considered in this study, but should be carefully assessed in the case of higher heating rates and/or temperatures. In particular, it is well known that concrete exposed to fire (i.e. to high temperatures) may exhibit important gas pressures (up to $4 \mathrm{MPa}$, e.g. [17]), which cannot be disregarded from the mechanical viewpoint.

In this model concrete is viewed as a porous material composed of a homogeneous matrix in which are dispersed spherical inclusions and penny-shaped ellipsoids representing porosity and microcracks, respectively. These two families of inclusions are supposed to have well separated dimensions in typical conditions, such that a two-step homogenization procedure may be applied to estimate the main mechanical and transfer parameters [1]. Indeed, capillary pores are commonly defined as the 'large' pores with size greater than $0.1-1 \mu \mathrm{m}$ up to a few hundred of $\mu \mathrm{m}$ (while pores of lower size are designated as inter hydrates and $\mathrm{C}-\mathrm{S}-\mathrm{H}$ pores), which is assumed much smaller than the ellipsoids radius representing microcracks for moderate damage states. We also suppose that they are connected such that both gaseous and liquid phase are subjected to the same pressure in the two inclusion families. Finally we make the hypothesis to simplify that the ellipsoids are identical and randomly oriented, this latter assumption being necessary to guarantee that the corresponding macroscopic damage variable remains isotropic. The ellipsoids distribution is then classically characterized by the density parameter $\rho=N a^{3}$, with $N$ the density number (i.e. the number of microcracks per volume) and $a$ the radius of the ellipsoids (see e.g. [18]). Denoting as $2 c$ the microcrack opening corresponding to the dimension of the ellipsoid in the revolution axis direction, the volume fraction of microcracks is $\phi_{c}=(4 \pi / 3) \rho X$, with $X=c / a$ the aspect ratio of the ellipsoid. We apply the interaction direct derivative (IDD) scheme developed by Zheng and Du [19] to estimate the mechanical and hydro-mechanical properties. For the microstructure representation and the two-step homogenization scheme as adopted here, the bulk and shear moduli introduced in Eq. (1) are then given by (see [1] for the detailed calculations):

$$
\begin{aligned}
\frac{k}{k_{s}} & =\left(1+\frac{\phi_{p} T_{p}^{h}}{1-\phi_{p}}\right)^{-1}\left(1+\frac{\rho \alpha_{I}^{h}}{1-\rho \alpha_{I I}^{h}}\right)^{-1}, \\
\frac{\mu}{\mu_{s}} & =\left(1+\frac{\phi_{p} T_{p}^{d}}{1-\phi_{p}}\right)^{-1}\left(1+\frac{\rho \alpha_{I}^{d}}{1-\rho \alpha_{I I}^{d}}\right)^{-1}
\end{aligned}
$$

where $T_{p}^{h}$ and $T_{p}^{d}$ are the hydrostatic and deviatoric parts, respectively, of the isotropic (dilute) strain localization tensor $\boldsymbol{T}_{p}^{s}=$ $\left(\boldsymbol{I}^{(4)}-\boldsymbol{\Sigma}_{p}^{s}\right)^{-1}$, with $\Sigma_{p}^{s}$ the Eshelby tensor of a spherical inclusion in the solid matrix and $I^{(4)}$ the fourth order identity tensor; $\alpha_{I}^{h}, \alpha_{I I}^{h}, \alpha_{I}^{d}$ and $\alpha_{I I}^{d}$ are coefficients resulting from an average procedure over all possible orientations of microcracks (see $[1,16]$ for further details); the subscript $s$ designates quantities relative to the solid phase; $\phi_{p}$ is the volume fraction of pores. Having defined the variable representing the isotropic defects at the macroscale and the behaviour of the damaged material, the next stage consists in characterizing the evolutions of the damage variable, which is simply chosen to be the density parameter $\rho$. We adopt the classical approach in which the evolutions of the internal variables are specified macroscopically by means of appropriate laws involving state variables. Following this simple and pragmatic approach, the evolutions of the damage variable $\rho$ are expressed by making use of the relation introduced by Mazars [20] specifying that the main parameter controlling these evolutions is the equivalent strain de- fined by $\tilde{\varepsilon}=\sqrt{\sum_{i}\left\langle\varepsilon_{i i}\right\rangle_{+}^{2}}$, with $\varepsilon_{i i}$ the principal strains and $\langle\cdot\rangle_{+}$the Macauley brackets. The damage evolutions are further proposed to be ruled by:

$\rho=\exp \left(\left(\frac{\tilde{\varepsilon}}{\varepsilon_{0}}\right)^{m}-1\right)-1$ if $\tilde{\varepsilon} \geqslant \varepsilon_{0}$ and $\sigma>0$

with the condition $\dot{\rho} \geqslant 0 ; m$ is a positive parameter and $\varepsilon_{0}$ corresponds to the initial strain threshold; $\sigma$ is the bulk stress defined by $\sigma=(\boldsymbol{\sigma}: \boldsymbol{I}) / 3$. In the numerical applications presented in Section 4 , as the essential source of damage is related to extensions, only damage due to tensile states of stresses is considered, and the parameters are set to the values $m=0.55$ and $\varepsilon_{0}=1 \times 10^{-4}$. Moreover, a non-local damage formulation is used for ensuring objective results in terms of damage and mechanical response with respect to the mesh size [21]. The internal parameter related to the non-local formulation is set to $l_{c}=0.025 \mathrm{~m}$.

Besides, to simplify the so-called load induced thermal strains (LITS, see e.g. [22]) are not accounted for, as they are assumed to be small relative to thermal and mechanical strains due to the moderate temperatures considered in this study. However, this assumption would deserve to be validated upon appropriate experimental measurements.

The evaluation of the Biot coefficient is based on the consideration that the macroscopic stress $\boldsymbol{\sigma}_{i}$ generated by any microscopic homogeneous eigenstresses (or strain-free stresses) $p_{i} \boldsymbol{I}$ acting in the inclusion family $i$ reads (see e.g. [23,24]):

$\boldsymbol{\sigma}_{i}=-\left\langle{ }^{\mathrm{T}} \boldsymbol{A}: p_{i} \boldsymbol{I}\right\rangle=-\phi_{i}\left\langle{ }^{\mathrm{T}} \boldsymbol{A}: p_{i} \boldsymbol{I}\right\rangle_{i}=-\phi_{i}{ }^{\mathrm{T}} \boldsymbol{A}_{i}: \boldsymbol{I} p_{i}$

where $\boldsymbol{A}$ is the strain localization tensor, $\langle\cdot\rangle$ and $\langle\cdot\rangle_{i}$ denote the average operations over the whole volume and the volume of phase $i$, respectively, and $\boldsymbol{A}_{i}=\langle\boldsymbol{A}\rangle_{i}$. We apply this equation to the case of our porous material subjected to the pore pressure $p_{l}$ in the volume fraction $\phi_{l}$. Indeed in our case $p_{l}$ can be interpreted as an eigenstress which develops in the inclusions formed by the space occupied by water. To evaluate $\phi_{l}$, we suppose that the same water pressure $p_{l}$ exerts in the two inclusion families of the material. We further adopt the hypothesis that the microcracks first totally desaturate before porosity begins to empty in the case of a desaturation of the material. Conversely, the microcracks are supposed to resaturate after porosity in the case of an imbibition process. With these definitions and assumptions, the effective Biot coefficient $b$ is obtained in the form $[1,16]$ :

$b=\frac{\rho \alpha_{I}^{h}\left(1+\phi_{p}\left(T_{p}^{h}-1\right)\right) \xi_{c}+\phi_{p} T_{p}^{h}\left(1-\rho \alpha_{I I}^{h}\right) \xi_{p}}{\left(1+\phi_{p}\left(T_{p}^{h}-1\right)\right)\left(1+\rho \alpha_{I}^{h}-\rho \alpha_{I I}^{h}\right)}$

where $\xi_{p}$ and $\xi_{c}$ are coefficients varying from 0 to 1 and indicating the saturation level of porosity and microcracks, respectively. They are defined as:

$\xi_{c}=\left[\left(1+\frac{\phi_{p}}{\phi_{c}}\right) S_{l}-\frac{\phi_{p}}{\phi_{c}}\right] H\left(S_{l}-S_{l p}\right)$,

$\xi_{p}=\left(1+\frac{\phi_{c}}{\phi_{p}}\right) S_{l}\left(1-H\left(S_{l}-S_{l p}\right)\right)+H\left(S_{l}-S_{l p}\right)$

where $S_{l}$ is the liquid saturation degree, $S_{l p}=\phi_{p} /\left(\phi_{c}+\phi_{p}\right)$ corresponds to the saturation degree at which microcracks are emptied while pores are filled by water, and $H$ is the Heaviside function. Note that this approach may be generalized without difficulty to an arbitrary number of pore and microcrack classes, provided they exhibit a size hierarchy [16]. It may further be extended quite easily to the more general case of ellipsoidal pores with isotropic spatial distribution [16].

Another remark concerns the simplification in the microstructure description, which is assumed here to be only composed of 
a homogeneous matrix in which are dispersed void inclusions. Indeed, some authors propose a more complex representation including various solid phases present at different scales, from the hardened cement paste (i.e. dimensions ranging from several $\mathrm{nm}$ to about one hundred of $\mu \mathrm{m}$ ) to the concrete with its typical characteristic dimension of about $10 \mathrm{~cm}$ (see e.g. [25-31]). Matrix-inclusion type morphologies and/or multi-layered composite sphere models are used in these studies. Again, to simplify and since the purpose of the present study mainly concerns the multiphysical behaviour of cementitious materials (in particular when subjected to complex non-linear phenomena consecutive to temperature increase and partially saturated conditions, which in general are not tackled in the aforementioned sophisticated micromechanical models due to their complexity), we keep in a first approach the basic microstructure description presented above and leave for future works the developments necessary for the integration of more realistic morphological and microstructural characteristics.

Due to the relatively low stress levels in the reinforcement rebars in the MAQBETH structure during the thermo-hydric loading which always remain far from the elasticity limit of the material, the steel mechanical behaviour is simply assumed as linear elastic (note that this assumption has been validated by the simulation results). It is further considered temperature-independent in the temperature range of this study (by contrast, the Young modulus of concrete evolves linearly as a function of the temperature, see Table 2 for the parameter values). We will further suppose classically in the simulations a perfect adherence between concrete and the steel rebars.

\subsubsection{Mass conservation equation}

The mass balance for water requires considering both its liquid and vapour form, thus leading for general situations to 2 equations which take classically the form (see e.g. $[4,32]$ ):

$$
\frac{\partial}{\partial \mathrm{t}}\left(\mathrm{m}_{l}\right)=-\nabla \cdot\left(\mathrm{m}_{l} \boldsymbol{v}_{l}\right)-\mu_{l \rightarrow v}+\dot{d}, \quad \frac{\partial}{\partial \mathrm{t}}\left(\mathrm{m}_{v}\right)=-\nabla \cdot\left(\mathrm{m}_{v} \boldsymbol{v}_{v}\right)+\mu_{l \rightarrow v}
$$

Table 2

Thermo-hydro-mechanical parameters for MAQBETH concrete.

\begin{tabular}{ll}
\hline Data & Value \\
\hline Initial porosity $\phi_{0}$ & 0.1 \\
Initial relative humidity $h_{r}^{0}$ & 0.96 \\
Initial permeability to Gas $k_{m g}^{0}$ & $1.0 \times 10^{-17} \mathrm{~m}^{2}$ \\
Gas permeability $k_{m g}\left(S_{l}=0\right)$ & $k_{m g}\left(S_{l}=0\right)=k_{m g}^{0} \exp (0.2 d)$ \\
Initial intrinsic permeability to liquid $k_{m l}^{0}$ & $k_{m l}^{0}=3 \times 10^{-5} k_{m g}^{0}$ \\
Water released due to dehydration & $d=0.018(T-60) \mathrm{kg} /{ }^{\circ} \mathrm{C}$ for \\
process $d$ [12] & $T \geqslant 60{ }^{\circ} \mathrm{C}, d=0$ otherwise \\
Evolution of porosity with $T$ & $\phi=\phi_{0}+d / 2280$ \\
Saturated concrete thermal conductivity & $2.3 \mathrm{~W} / \mathrm{m}{ }^{\circ} \mathrm{C}$ \\
$\quad \lambda_{20}$ & $1.9 \mathrm{~W} / \mathrm{m}^{\circ}{ }^{\circ} \mathrm{C}$ \\
Unsaturated concrete thermal & \\
conductivity $\lambda_{60}$ & $750 \mathrm{~J} / \mathrm{kg}{ }^{\circ} \mathrm{C}$ \\
Thermal capacity of anhydrous cement $C_{c}$ & $800 \mathrm{~J} / \mathrm{kg}{ }^{\circ} \mathrm{C}$ \\
Thermal capacity of aggregates $C_{a}$ & $4184 \mathrm{~J} / \mathrm{kg}{ }^{\circ} \mathrm{C}$ \\
Thermal capacity of water $C_{w}$ & $3760 \mathrm{~J} / \mathrm{kg}{ }^{\circ} \mathrm{C}$ \\
Thermal capacity of bound water $C_{b w}$ & $2500 \mathrm{~kJ}$ \\
Enthalpy of dehydration $L_{w \rightarrow g w}$ & $46 \mathrm{~W} / \mathrm{m}{ }^{\circ} \mathrm{C}$ \\
Steel thermal conductivity $\lambda_{s}$ & $450 \mathrm{~J} / \mathrm{kg} \cdot{ }^{\circ} \mathrm{C}$ \\
Thermal capacity of steel $C_{s}$ & $7850 \mathrm{~kg} / \mathrm{m}^{3}$ \\
Volumetric mass of steel & $38.9 \mathrm{GPa}\left(20{ }^{\circ} \mathrm{C}\right)$ to $20.4 \mathrm{GPa}$ \\
Concrete elasticity modulus $E_{c}(T)($ linear & $\left(250{ }^{\circ} \mathrm{C}\right)$ \\
evolution as a function of $T)$ & 0.22 \\
Poisson coefficients of concrete $v_{c}$ & $190 \mathrm{GPa}\left(20-250{ }^{\circ} \mathrm{C}\right)$ \\
Steel elasticity modulus $E_{s}(T)$ & 0.30 \\
Poisson coefficients of steel $v_{s}$ & $11.0 \times 10^{-6} \mathrm{C}^{-1}$ \\
Concrete thermal dilatation coefficient $\alpha$ & $10 \mathrm{~W} / \mathrm{m}{ }^{\circ} \mathrm{C}$ \\
Equivalent convection coefficient $h$ & \\
\hline & \\
&
\end{tabular}

in which $\mathrm{m}_{l}=\phi \rho_{l} S_{l}$ and $\mathrm{m}_{v}=\phi \rho_{v}\left(1-S_{l}\right)$ are the mass of liquid water and vapour per unit volume of material, respectively; $\phi$ is the total porosity; $\rho_{i}$ designates the density of the water in phase $i, i \in\{l, v\}$ for liquid and vapour; $\mu_{l \rightarrow v}$ is the rate of evaporation of water per unit volume; $\boldsymbol{v}_{i}$ is the velocity of phase $i$ and $\dot{d}$ represents the rate of water released in the porosity due to the dehydration process of the hydrated solid products when temperature rises (see Table 2 for the numerical values). This latter quantity appears as a source term in the mass balance Eq. (7) and may be related to the mass of solid skeleton $\mathrm{m}_{s}$ through $\partial \mathrm{m}_{s} / \partial t=-\dot{d}$.

From the Eq. (7) and with the assumption that the gas phase is composed only of vapour [12], the mass balance equation of water can be written as [1]:

$$
\begin{aligned}
& {\left[\frac{\phi}{\rho_{l v}}\left(S_{l} \frac{\partial \rho_{l}}{\partial T}+S_{v} \frac{\partial \rho_{v}}{\partial T}\right)+\varpi \frac{\partial S_{l}}{\partial T}+\left(\phi_{d}^{\prime}+3 \alpha \frac{k}{k_{s}}-3 \alpha_{s}(1-\phi)\right)\right] \frac{\partial T}{\partial t}} \\
& \quad+b^{*} \frac{\partial \varepsilon}{\partial t}+\frac{\Xi}{k_{s}} \frac{\partial \rho}{\partial t}+\frac{1}{\rho_{l v}} \nabla \cdot\left(\boldsymbol{w}_{l}+\boldsymbol{w}_{v}\right) \\
& +\left[-\varpi \frac{\partial S_{l}}{\partial p_{c}}+\frac{b-\phi S_{l}}{k_{s}}+\frac{\phi}{\rho_{l v}}\left(S_{l} \frac{\partial \rho_{l}}{\partial p_{l}}+S_{v} \frac{\partial \rho_{v}}{\partial p_{l}}\right)\right] \frac{\partial p_{l}}{\partial t}=\frac{\dot{d}}{\rho_{l v}}
\end{aligned}
$$

in which $\phi_{d}$ is the porosity fraction due to dehydration of the solid phase, $\Xi=p_{l} \partial b / \partial \rho-(\varepsilon-3 \alpha \theta) \partial k / \partial \rho+\phi_{c}^{\prime}+\varpi k_{s} \partial S_{l} / \partial \rho, b^{*}$ is the Biot coefficient in saturated conditions, $\varpi=\phi\left(\rho_{l}-\rho_{v}\right) / \rho_{l v}-p_{l} /$ $k_{s}\left(\phi-\partial b / \partial S_{l}\right)$, and $\rho_{l v}=S_{l} \rho_{l}+S_{v} \rho_{v}$. It is also implicitly supposed that $\partial k_{s} / \partial T=0, k_{s} \gg \sigma_{s}-p_{l}$ with $\sigma_{s}$ the bulk stress of the solid phase, and that $S_{l}$ varies as a function of $T$ and of the capillary pressure $p_{c}$. Classically, we assume that $p_{c}$ is linked to the relative humidity defined by $h_{r}=p_{v} / p_{v s}$, with $p_{v s}$ the vapour pressure at saturation, via the Kelvin's law:

$p_{c}=-\rho_{l} \frac{R T}{M_{v}} \ln h_{r}$

where $M_{v}$ and $R$ are the molar mass of water and the ideal gas constant, respectively. Consequently $S_{l}$ may by as well expressed as a function of $h_{r}$ instead of $p_{c}$. The theoretical (and numerical) description of the corresponding sorption curves $S_{l}\left(h_{r}, T\right)$, which integrate complex microstructural and physical features, in particular in terms of pore size distribution, connectedness and adsorption phenomena, will be the focus of Section 3.2. Note that the very definition of the capillary pressure $p_{c}$ involves both liquid and gas pressure as $p_{c}=p_{m}-p_{l}$, with $p_{m}$ the pressure of the gas phase, equal in our study to $p_{v}$. Since the gas pressure is assumed here to be negligible relative to the liquid one from the mechanical point of view, we adopt the simplification $p_{c} \approx-p_{l}$. The hypothesis of disregarding the dry air in the moisture transport process has been discussed in details in [1], and has proven to be reasonable in [14] in the context of moderate temperature conditions.

The classical Darcy's law is used for expressing the mass flux as:

$\boldsymbol{w}_{i}=-\frac{\rho_{i} \boldsymbol{K}_{i}}{\eta_{i}} k_{r i}\left(S_{l}\right) \nabla p_{i}$

where $\boldsymbol{K}_{i}, k_{r i}$ and $\eta_{i}$ are the isotropic permeability tensor, the relative permeability and the dynamic viscosity of the phase $i$, respectively. We denote $k_{e i}$ the permeability coefficient such that $k_{e i}\left(S_{l}, \rho\right) \boldsymbol{I}=\boldsymbol{K}_{i} k_{r i}\left(S_{l}\right)$. Since the knowledge of their evolutions is crucial for obtaining an accurate evaluation of the hydric state through Eqs. (8)-(10), the permeability coefficients $k_{e i}$ of the material are estimated as a function of the damage state $\rho$ and saturation degree $S_{l}$, by making use of the Generalized Effective Media (GEM) formulation [33]. We suppose further that the flow in the microcracks can be approximated by a Poiseuille flow occurring between two parallel plates separated by the distance $2 c$. Designating by $k_{c}$ the permeability of the cracks, we then have $k_{c}=c^{2} / 3=(\rho / N)^{2 / 3} X^{2} / 3$. Let $k_{m j}$ be the permeability to water $(j=l)$ or gas $(j=g)$ of the matrix composed of the solid phase and the porosity; $k_{m l}$ and $k_{m g}$ stand then for the 
permeability of the undamaged material, and may be experimentally determined for each of the fluid phases. The widely used relative permeability function introduced by van Genuchten [34] is further used to modify the effective value of $k_{m l}$ as a function of $S_{l}$, whereas the correction function proposed by [35] is adopted to adjust the one of $k_{m g}$ (see Table 3). Note that the transport of adsorbed water is assumed to simplify to be accounted for in the liquid relative permeability function, and is then not considered independently [8].

Applying the GEM formulation to the damaged material where the role of the inclusion phase is played by the microcracks and the matrix by the undamaged material, and making use of the scenario describing the saturation and desaturation process of microcracks and porosity as defined by Eq. (6), the following expressions for the permeability to liquid $k_{e l}$ and to gas $k_{e g}$ were found in [1]: are the mass heat capacities of the dry solid phase and of the bound water, respectively; $\left(d_{0}-d\right)$ corresponds to the current mass of bound water. The terms of heat transported by fluid convection $\left(\boldsymbol{w}_{l} C_{p l}+\boldsymbol{w}_{v} C_{p v}\right) \nabla T$ and heat dissipation due to the liquid phase compressibility $\boldsymbol{w}_{v} / \rho_{v} \nabla p_{v}$ are assumed both negligible [36]. The heat of vaporization is expressed by $L_{l \rightarrow v}=T\left(s_{v}-s_{l}\right)$ with $s_{i}$ the entropy of the phase $i$, and by analogy the heat of dehydration is defined by $L_{s \rightarrow l}=T\left(s_{s}-s_{b w}\right)$ [37].

The heat flux is classically expressed via the Fourier law:

$\mathbf{q}=-\lambda\left(S_{l}, d\right) \nabla T$

with $\lambda\left(S_{l}, d\right)$ the thermal conductivity coefficient (note that in the Eq. (14) we assume an isotropic behaviour); the experimental function $\lambda\left(S_{l}, d\right)=\lambda_{60}+\Delta \lambda\left(S_{l} / S_{l o}\right)-k_{d} d$ was proposed in [12], where

$\left.k_{e l}=\left[\frac{1}{2}\left(\alpha+\sqrt{\alpha^{2}+4\left(k_{c} k_{m l}\right)^{1 / t_{l}}\left[\xi_{c} \phi_{c} \chi+\chi\left(1-\xi_{c} \phi_{c}-\left(1-\xi_{c}\right) \phi_{c}(1+\chi)\right)\right.}\right]\right)\right]^{t_{l}}$

$k_{e g}=\left[\frac{1}{2}\left(\alpha^{\prime}+\sqrt{\alpha^{\prime 2}+4\left(k_{c} k_{m g}\right)^{1 / t_{g}}\left[\left(1-\xi_{c}\right) \phi_{c} \chi+\chi\left(1-\left(1-\xi_{c}\right) \phi_{c}-\xi_{c} \phi_{c}(1+\chi)\right)\right]}\right)\right]^{\operatorname{tg}_{g}}$

with $\alpha^{\prime}=k_{m g}^{1 / t_{g}}\left(1-\phi_{c}(1+\chi)\right)+k_{c}^{1 / t_{l}}\left(\left(1-\xi_{c}\right) \phi_{c}+\chi\left(\left(1-\xi_{c}\right) \phi_{c}-1\right)\right)$, $\alpha=k_{m l}^{1 / t_{l}}\left(1-\phi_{c}(1+\chi)\right)+k_{c}^{1 / t_{l}}\left(\xi_{c} \phi_{c}+\chi\left(\xi_{c} \phi_{c}-1\right)\right), \chi=\phi_{c c} /\left(1-\phi_{c c}\right), t_{l}$ and $t_{g}$ are parameters which values are adjusted so that the maximal increase of permeability due to damage does not exceed $10^{4}$. The numerical simulations have been carried out with the values of Tables 2 and 3 , and $X=1 \times 10^{-4}, t_{l}=3, t_{g}=3$.

As previously mentioned, we assume that the steel reinforcement rebars play no role in the hydric state of the concrete. We then neglect the local disturbance involved by the presence of these rebars, which however probably affect slightly the mass transfers in their vicinity.

\subsubsection{Heat equation}

The entropy conservation equation is classically written in the form (see [1]):

$$
\begin{aligned}
& c\left(S_{l}, d\right) \frac{\partial T}{\partial t}+\left(\boldsymbol{w}_{l} C_{p l}+\boldsymbol{w}_{v} C_{p v}\right) \nabla T-\frac{\boldsymbol{w}_{v}}{\rho_{v}} \cdot \nabla p_{v} \\
& =-\nabla \cdot \boldsymbol{q}-L_{l \rightarrow v} \mu_{l \rightarrow v}-L_{s \rightarrow l} \dot{d}
\end{aligned}
$$

where $c\left(S_{l}, d\right)=m_{d s} C_{d s}+\phi \rho_{l} S_{l} C_{p l}+\phi \rho_{\nu}\left(1-S_{l}\right) C_{p v}+\left(d_{0}-d\right) T C_{b w}$ is the heat capacity of the concrete material; $C_{p l}$ and $C_{p v}$ are the mass heat capacities of the free (bulk) water and vapour, respectively; $m_{d s}$ is the mass of cement and aggregate per unit volume; $C_{d s}$ and $C_{b w}$

Table 3

Main functions introduced for the simulations.

\begin{tabular}{lll}
\hline Data & Expression & Refs. \\
\hline $\begin{array}{c}\text { Liquid water } \\
\text { density }\end{array}$ & $\rho_{l}=314.4+685.6\left[1-\left(\frac{T-273.15}{374.14}\right)^{\frac{1}{0.55}}\right]^{0.55}\left[\mathrm{~kg} / \mathrm{m}^{3}\right]$ & {$[54]$} \\
Dynamic viscosity & - liquid water: & {$[55]$} \\
& $\eta_{l}(T)=2.414 \times 10^{5} \exp \left(\frac{570.58058}{T+133.15}\right)[\mathrm{kg} / \mathrm{m} / \mathrm{s}]$ & \\
& - vapour: $\eta_{l}(T)=3.85 \times 10^{-8} T+10^{-5}[\mathrm{~kg} / \mathrm{m} / \mathrm{s}]$ & {$[56]$} \\
Vapor saturation & $p_{v s}(T)=p_{a t m} \exp \left[4871.3 \frac{T-100}{373.15} T\right][\mathrm{Pa}]$, with & {$[54]$} \\
pressure & $p_{a t m}=101325$ Pa & \\
Relative & - liquid relative permeability: & {$[34]$} \\
permeability & $k_{r l}\left(S_{l}\right)=\sqrt{S_{l}}\left[1-\left(1-S_{l}^{1 / m}\right)^{m}\right]^{2}$ & \\
& - vapor permeability: $k_{m g}=K k_{r g}\left[1+\left(a / p_{g}\right)\right]$ & {$[35]$} \\
& with: $k_{r g}\left(S_{l}\right)=\left(1-S_{l}\right)^{p}\left[1-S_{l}^{\frac{1}{m}}\right]^{2 m}$ & \\
& and: $a=11.1, p=5.5$ and $m=0.56$ & \\
\hline
\end{tabular}

$\Delta \lambda=\lambda_{20}-\lambda_{60}, \lambda_{20}$ and $\lambda_{60}$ being the saturated and unsaturated concrete thermal conductivity [1].

The contribution of the steel reinforcement rebars is also taken into account via the classical heat equation (see Table 2 for the thermal properties of steel and concrete). However the numerical results show a negligible influence of these rebars on the temperature evolutions in the structure, such that they could be ignored, from the thermal point of view, in the simulations.

\subsection{Isotherm sorption curves}

This subsection presents and details the model used for capturing the temperature effects on the sorption curves $S_{l}\left(h_{r}, T\right)$. The coupling and implementation of this model into the THMs code are among the main contributions of the paper. These temperature effects are specifically taken into account by introducing the isosteric heat of adsorption, while we conserve the classical macroscopic approach which assumes that the sorption curves incorporate basically microstructural information (mainly in terms of pore size distribution). There are only very few results in the scientific literature about the influence of temperature on the concrete water retention curve, see e.g. [11,38-43] for more information (note that in these studies the maximal temperature is $80^{\circ} \mathrm{C}$ ). Temperature appears to have an important impact on the retention curve, as illustrated for example in the work of [38]. The main following features appear when temperature increases:

- the general isotherm curve shape is modified (more pronounced non-linearity),

- the saturation at equilibrium with an arbitrary $h_{r}$ is reduced,

- the saturation decrease is observed over the whole $h_{r}$ range and the higher the temperature, the greater the reduction.

It is noteworthy that there is no temperature threshold (these modifications appear whatever the temperature increase) and these effects are more pronounced on the desorption path. The origin of this phenomenon has been discussed in [43] and it is believed that for temperatures lower than $80^{\circ} \mathrm{C}$ the so-called "thermal desorption" is the major phenomenon at stake. The latter corresponds to the shift of equilibrium between adsorbed water and vapour induced by a temperature modification. Adsorption is an exothermic process, i.e. heat is released when water molecules 
get adsorbed. As a consequence, a temperature increase hinders adsorption and promotes desorption, following the law of Van't Hoff [44]. This effect can be efficiently described using the wellknown Clausius-Clapeyron equation (see e.g. [10]):

$Q_{s t}(w)=-R\left(\frac{\partial\left(\ln p_{v}\right)}{\partial(1 / T)}\right)_{w}$

where $Q_{s t}$ is the isosteric heat of adsorption and stands for the binding energy between the water molecules and the cementitious material, and $w$ is the mass water content (defined as the ratio of the mass of water over the masse of dry solid) at equilibrium with the vapour pressure $p_{v}$ (note that $w$ and $S_{l}$ are linked by $S_{l}=w / w_{\text {sat }}$ with $w_{\text {sat }}$ the water content at saturation).

For any given cementitious material, knowing the isosteric heat as well as the isotherm for one reference temperature $T_{0}$, one can easily estimate the isotherm for any other temperature $T$ by integration of Eq. (15) between $T_{0}$ and $T$. The relative humidity $h_{r}$ $(T, w)$ at equilibrium with the water content $w$ at the temperature $T$ is then directly deduced from the one at equilibrium with the content $w$ at the reference temperature $T_{0}$, i.e. $h_{r}\left(T_{0}, w\right)$. According to Eq. (15) and recalling that the vapour behaves as an ideal gas, we get [10]:

$h_{r}(T, w)=h_{r}\left(T_{0}, w\right) \frac{p_{v s}\left(T_{0}\right)}{p_{v s}(T)} \exp \left(-\frac{Q_{s t}(w)}{R} \frac{T_{0}-T}{T T_{0}}\right)$

where use has been made of the definition of $h_{r}$ introduced in Eq. (9). Eq. (16) then shows that $h_{r}(T, w)$ is proportional to $h_{r}\left(T_{0}, w\right)$, the coefficient of proportionality being dependent on $T$ and on $w$ (or equivalently $S_{l}$ ) through $Q_{s t}$. It is noteworthy that in the expression (16), the microstructural changes induced by temperature (cracking, neo-porosity generated by hydrate dissolution) are implicitly neglected. This approach was nonetheless proven to be valid and very helpful to describe the temperature effects for temperatures lower than $80^{\circ} \mathrm{C}$ in [10]. In this study we assume that it can be extended up to $200^{\circ} \mathrm{C}$, although for such conditions the microstructural modifications are not expected to be negligible any more. However we remark that for growing temperatures the desorption curves become more and more flat, that is, the saturation degree significantly decreases at given relative humidities, and approach 0 for $T>150-200^{\circ} \mathrm{C}$. This implies that the consequences of microstructure changes are likely to be reduced since all curves seem to tend towards 0 (see Fig. 4 for an illustration: the curves at $T=100^{\circ} \mathrm{C}$ is not very far from the one at $T=200^{\circ} \mathrm{C}$, which is near to 0 ). Therefore it is believed that this simplified approach is able to capture the main phenomena at work, and that the sorption curves evolutions are reasonably described.

We apply this method by making use, without loss of generality, of the well-known Guggenheim-Anderson-de Boer (GAB) model for describing the water sorption curve, which is known to correctly fit the experimental data over the whole range of relative humidity for most materials $[45,46]$. The GAB model takes the form:

$w\left(h_{r}\right)=\frac{C_{G} k_{G} w_{m} h_{r}}{\left(1-k_{G} h_{r}\right)\left(1+\left(C_{G}-1\right) k_{G} h_{r}\right)}$

where $C_{G}, k_{G}$ and $w_{m}$ are constant parameters. The relations (16) and (17) lead to an implicit set of equations since $Q_{s t}(w)$ depends on $h_{r}$ via Eq. (17). Then, except for very special cases, $h_{r}$ cannot be in general calculated explicitly from Eq. (16). In the following we will use the values of $Q_{s t}(w)$ identified in [10] (see Table 4 in this reference) on two experimental desorption curves obtained at 30 and $80^{\circ} \mathrm{C}$ for the same concrete as considered in this study. The $w$ vs. $h_{r}$ experimental data (symbols) and numerical results (lines) obtained with the model are plotted on Fig. 3. The analytical expression used for $p_{v s}(T)$ is indicated in Table 3, and the values of the GAB parameters

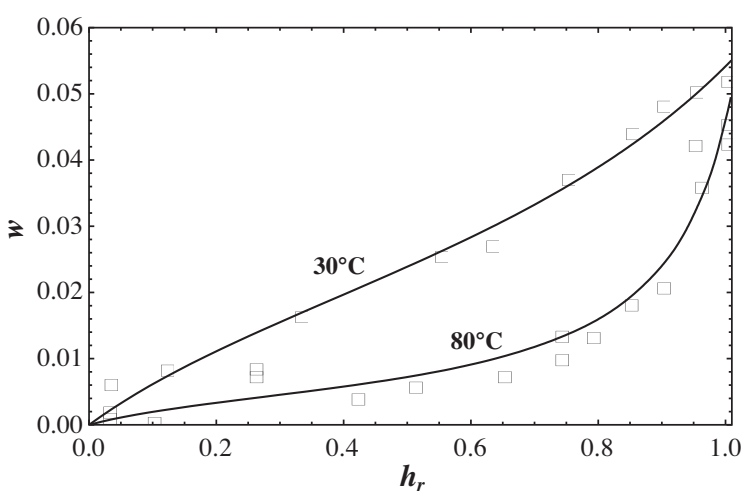

Fig. 3. Experimental (symbols, $[10]$ ) and numerical (lines) water content $w$ vs. relative humidity $h_{r}$ desorption curves at 30 and $80^{\circ} \mathrm{C}$.

are $C_{G}=4.69, k_{G}=0.592$ and $w_{m}=0.02534$. We observe that the temperature influences significantly the isotherm curves, and that the simulations fit well the experiments for both considered temperatures.

The model is now extended for temperatures up to $200{ }^{\circ} \mathrm{C}$, corresponding to the external temperature applied to the MAQBETH mock-up. Fig. 4 shows the numerical desorption curves in terms of $S_{l}$ vs. $h_{r}$ obtained at 4 different temperatures ranging from 20 to $200{ }^{\circ} \mathrm{C}$. Again, the effects of the temperature increase appear clearly: at $200{ }^{\circ} \mathrm{C}$ the saturation degree is estimated at about 0.05 at $h_{r}=1$, meaning that the quantity of adsorbed water is much lower than in the $20^{\circ} \mathrm{C}$ case. From the simulation point of view, the fact that at $h_{r}=1$ the saturation degree $S_{l}$ can be largely inferior to 1 for temperatures greater than about $70-80^{\circ} \mathrm{C}$ may lead to serious computational difficulties. Moreover, we consider that there is a priori no physical reason justifying that the material may never be totally saturated for such moderate temperatures, at least for certain particular conditions. Consequently, we assume that this saturation is effectively reached for $h_{r}=1$, which leads to an abrupt variation of the sorption curves near this value for elevated temperatures. We propose then to artificially modify the curves for $h_{r}>h_{r T}, h_{r T}$ being an arbitrary value set here to 0.94 , such that $h_{r}=1$ corresponds to $S_{l}=1$. A simple parabolic form is adopted for the modified part of the curves, which permits to impose a continuity condition on the derivative $\partial S_{l} / \partial h_{r}$ at $h_{r}=h_{r T}$. The resulting modified sorption curves are shown on Fig. 4 in thick lines, while for $h_{r}>h_{r T}$ the non-modified curves obtained with Eqs. (16) and (17) are drawn in dotted lines. Clearly enough, with the adaptation introduced for $h_{r} \geqslant h_{r T}$, the obtained curves exhibit strong

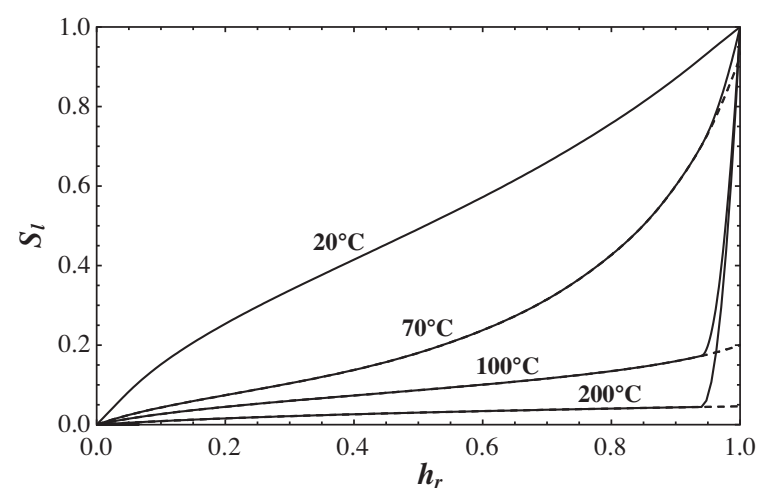

Fig. 4. Numerical desorption curves obtained at different temperatures ranging from 20 to $200^{\circ} \mathrm{C}$; for $h_{r}>h_{r T}=0.94$, the thick lines are parabolic curves such that $S_{l}=1$ for $h_{r}=1$, while the curves obtained with Eqs. (16) and (17) are in dotted lines. 
variations for high $h_{r}$, which will be the cause of numerical convergence problems as will be explained in the next section.

Note that in this approach we have supposed to simplify that other factors affecting the transport properties, in particular the relative permeability $k_{r l}$ introduced in Eq. (10), do not evolve as a function of temperature. This aspect regarding the effects of $T$ on $k_{r l}$ will be investigated in a subsequent contribution.

It is worth mentioning that previous studies have dealt with temperature dependency on the sorption curves without resorting on Eq. (16) based on the use of isosteric heat of sorption, but instead by introducing empirical evolution laws [47-49]. Though less marked, the curves obtained show the same trends as in Fig. 4, i.e. a significant decrease of the saturation degree at given $h_{r}$ for increasing temperatures. Interestingly, Bazant and Thonguthai $[47,48]$ also propose to modify the curves for $h_{r}>0.96$ to reduce the abrupt transition saturated - partially saturated state near $h_{r}=1$.

\section{Numerical results}

\subsection{Numerical procedure and simulations}

The governing equations of the THMs model are solved numerically by the finite element (FE) method for the discretization of the space domain, whereas the time is discretized by means of the classical $\theta$-method with $\theta=0.5$, corresponding to a Crank-Nicholson scheme. The FE code Cast3M developed by the French Atomic Energy Agency (CEA) is used for the simulations [50]. The model is implemented in a module written in object-oriented programming language named Gibiane, and takes advantage of the Cast3M thermal formulation for solving both balance equations, i.e. heat and mass water conservation equations. A partitioned procedure is applied: each of these equations is solved via an iterative procedure for the corresponding variable of the system, while keeping the others constant. The global solution of the two equations describing the thermo-hydric behaviour of the material, i.e. the final values of the primary variables $T$ and $p_{l}$, is achieved by means of a Picard iterative procedure at every time step. It has been shown that, except regarding damage, mechanics has only a negligible impact on the thermo-hydric response (mechanics appears only in the mass conservation Eq. (8) via the terms involving the time derivative of $\varepsilon$ ), see [1]. In the resolution method retained, the mechanical parameters are simply evaluated at each time step with the value of temperature and saturation degree (or equivalently $p_{l}$ ) obtained at the end of this step. Then, by keeping the damage state evaluated in the preceding time step for the thermo-hydric equations, the mechanical equilibrium equation does not need to be included in the TH loop and can be simply concatenated. To solve this equation (i.e. to determine the unknown displacement field), iterations are however required since the material behaviour is nonlinear elastic. The Newton-Raphson method is then used to achieve this resolution.

The simulations of the MAQBETH behaviour have been performed with two different meshes for modelling the concrete structure, one for solving the $\mathrm{TH}$ conservation equations and the other for the mechanics problem. Indeed, in the case of the TH problem, significant gradients of the unknowns $T$ and $p_{l}$ arise near the structure surfaces during the thermal loading. These gradients require a fine mesh in the direction perpendicular to theses surfaces to achieve convergence and obtain an accurate solution, in particular for the water mass conservation equation. This is why the adopted $\mathrm{TH}$ mesh contains much more elements by unit of length in the thickness of the structure than in its height (see Fig. 5 left). The mechanics mesh comprises square elements and is therefore more adapted to such problems; it is shown on Fig. 5 right, together with the segments representing the vertical

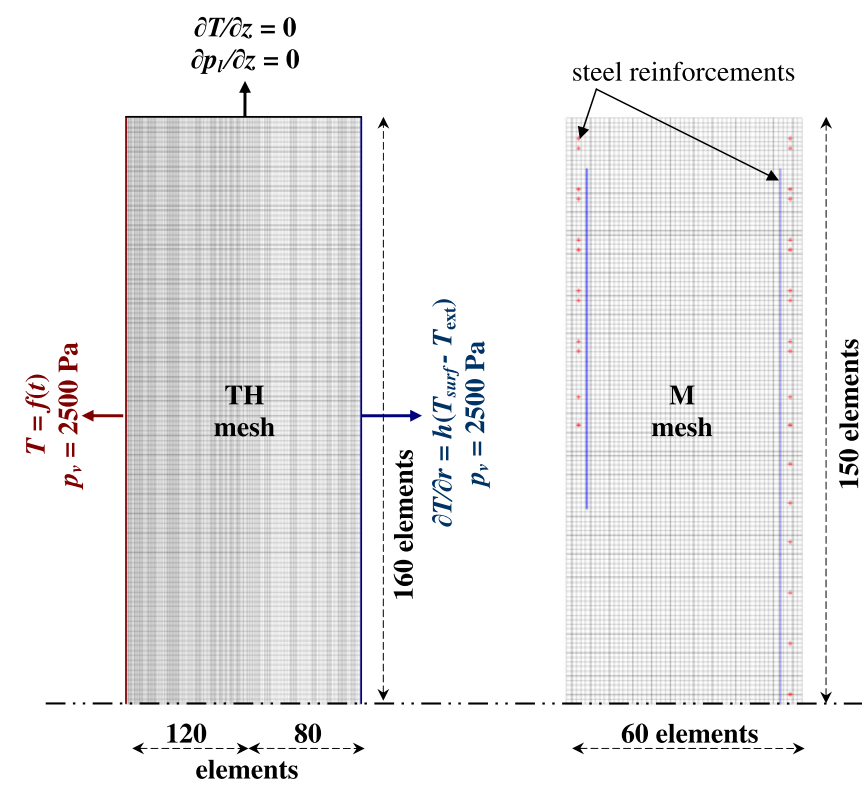

Fig. 5. Thermo-hydric (left) and mechanical (right) meshes with boundary conditions.

reinforcements rebars (blue) and the points representing the circular ones (red). Note that due to the geometrical and loading symmetry conditions, only half of the structure is modelled in a 2D axisymmetric formulation, with 4-nodes linear elements for concrete. The boundary conditions imposed in the simulations are indicated on Fig. 5, and the thermal loading applied on the inner surface is depicted on Fig. 6. The constant vapour pressure $p_{v}=2500$ Pa prescribed at both internal and external surfaces leads to a temporal decrease of $h_{r}$ (and then of $S_{l}$ ), as a consequence of the saturation vapour pressure $p_{v s}$ which augments with $T$ (see Table 3 ) and of the definition of $h_{r}=p_{v} / p_{v s}$. This vapour pressure value is assumed to be the one of the environment surrounding the structure. The loading temperature indicated on Fig. 6 is directly applied on the internal surface as Dirichlet conditions, while a constant exterior temperature of $T_{\text {ext }}=20^{\circ} \mathrm{C}$ and an equivalent convective condition $\left(h=10 \mathrm{~W} / \mathrm{m} /{ }^{\circ} \mathrm{C}\right)$ is prescribed at the external one.

The main parameters for concrete and steel are listed in Tables 1 and 2. Most of these parameters have been determined experimentally through the CEA research program on high-strength concrete behaviour at moderate temperature [51,52]. The liquid permeability $k_{m l}^{0}$ and the evolution of gas permeability as a function of dehydration $k_{m g}^{(d)}$ are adjusted to fit at best the experimental

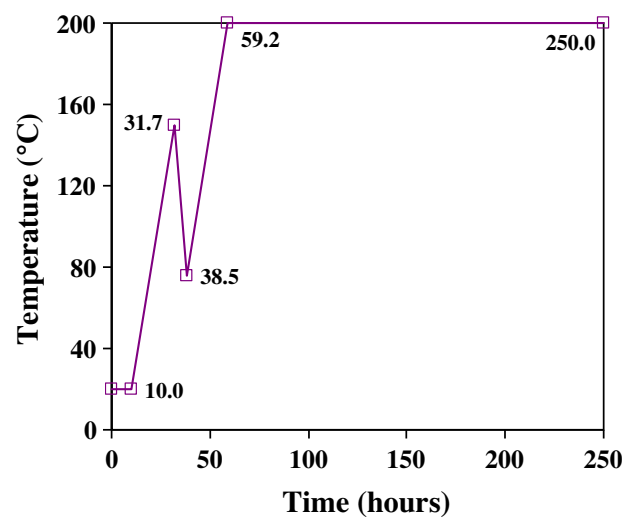

Fig. 6. Thermal loading on the inner surface of the structure as a function of time. 
results. The initial conditions consist in a stress and strain free state, a relative humidity of 0.96 and a temperature of $20^{\circ} \mathrm{C}$.

\subsection{Analysis of the numerical results}

We present in this subsection the main numerical results obtained on the MAQBETH structure with the model and the conditions defined previously. These results are compared to experimental data in terms of time evolutions of temperature, relative humidity and gas pressure profiles at mid-height of the structure (corresponding to the symmetry plane), and strain evolution at the internal surface.

Fig. 7 presents the numerical (lines) and experimental (symbols, [12]) radial profiles of temperature for different times. On this Figure and the following ones, the distance $r=0$ and $r=0.6 \mathrm{~m}$ correspond to the inner and outer surface of the structure, respectively. We observe that simulations and experiments are in good agreement, although some discrepancies appear in the vicinity of the internal longitudinal steel reinforcement (sensor positioned at $r=0.043 \mathrm{~m}$ ). This may be due to measurement or sensor location perturbations caused by the steel rebars. This satisfying confrontation proves that the model correctly reproduces the temperature evolutions inside the structure. Besides, the value of the equivalent convection coefficient $h$ adopted for prescribing the temperature at the external surface appears to be relatively well calibrated.

Fig. 8 presents the numerical (lines) and experimental (symbols, [12]) radial profiles of relative humidity (up), and corresponding numerical profiles of liquid saturation degree (down) obtained in the undamaged structure at various times. The simulated $h_{r}$ profiles appear in reasonably good agreement with experiments, which is not surprising since, as mentioned above, $k_{m l}^{0}$ and $k_{m g}^{(d)}$ were adjusted to that aim. Both numerical and experimental results clearly show that during heating $h_{r}$ gradually increases from a (quasi-) homogeneous constant value throughout the structure to almost $100 \%$. This is due partly to the resaturation of the porosity which follows from the dehydration of the hydrated phases caused by the temperature rise (see Fig. 8 down where we can see an increase of $S_{l}$ in the warmer zones), and also to the temperature dependency of the sorption curves. Indeed, these curves indicate that, for a given saturation degree, $h_{r}$ tends to increase upon heating. This point appears more clearly in the colder zone of the structure, for about $r>0.4 \mathrm{~m}$, where the water release in the porosity due to dehydration is very limited or inexistent (recall that $\dot{d}=0$ for $T<60^{\circ} \mathrm{C}$ ). It can be seen that in this region $h_{r}$ also raises and

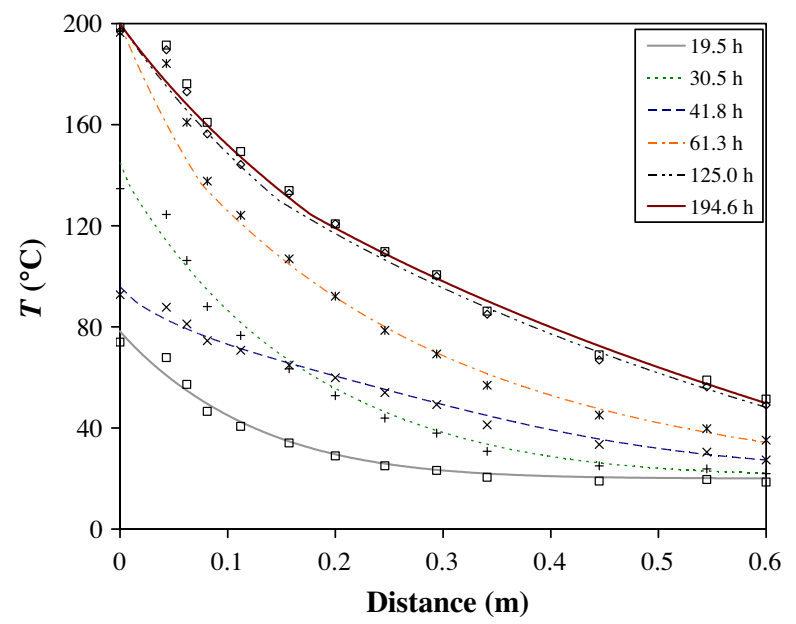

Fig. 7. Experimental (symbols, [12]) and numerical (lines) profiles of temperature as a function of the radial distance from the internal surface at different times.
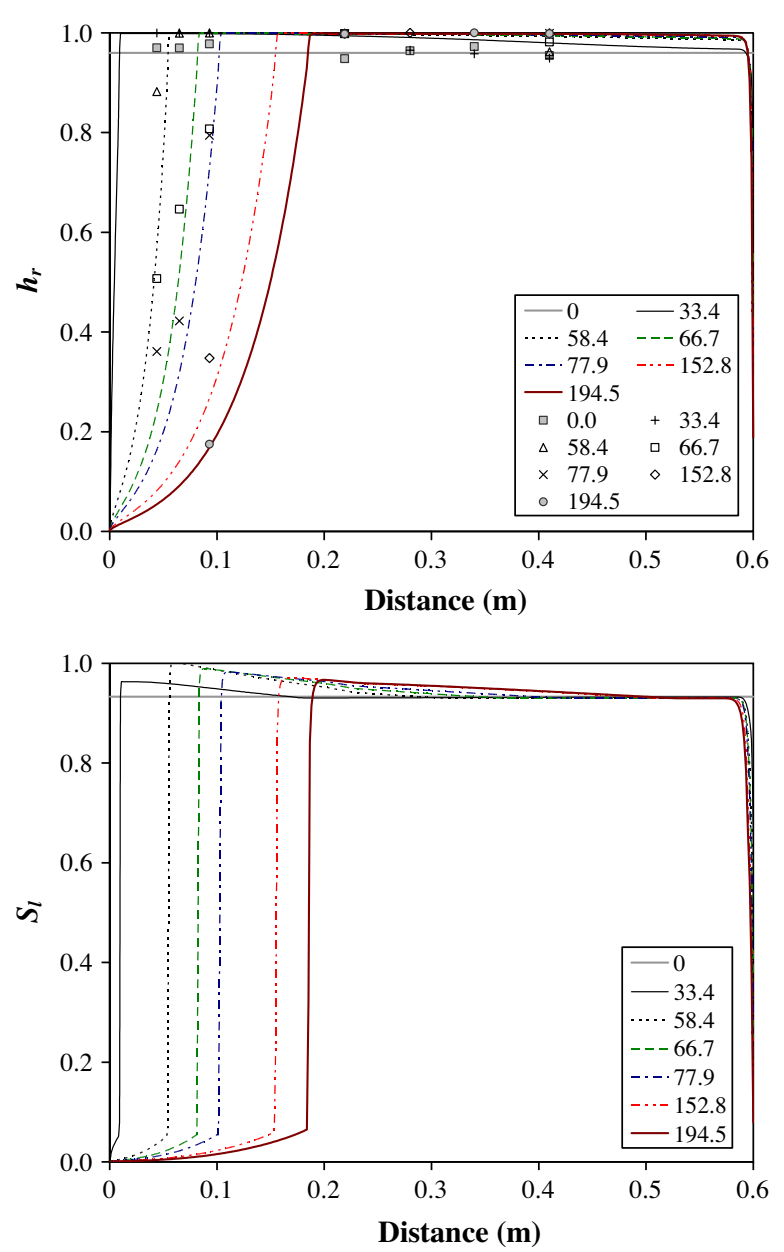

Fig. 8. Profiles of relative humidity $h_{r}$ (up) and liquid saturation $S_{l}$ (down) as a function of the radial distance from the inner surface at different times (hours). The experimental data of $h_{r}$ are presented in symbols ([12]) and the numerical results in lines.

approaches 1 while $S_{l}$ variations remain very small, which can be mainly explained by the temperature-dependant desorption curves. Note that both $h_{r}$ and $S_{l}$ are near zero at $r=0$ (i.e. at the heated surface), and that the profiles of saturation exhibit a very abrupt front, from about $S_{l}=0.07$ to 0.95 . This front is the direct consequence of the strong variations of the saturation in the desorption curves of Fig. 4 for $h_{r}>0.94$. Such behaviour is problematic from the numerical point of view as it leads to convergence difficulties, and requires a fine mesh not only in the neighbouring of the surface subjected to drying, but also in the entire region affected by the front propagation. It will be seen in the next subsection that the saturation profiles obtained with a temperatureindependent sorption curve are very different.

The numerical (lines) and experimental (symbols, [12]) radial profiles of gas pressure obtained at mid-plan of the undamaged structure are depicted on Fig. 9 for various times. We recall that in the model the gas phase is only constituted of vapour, which means that the numerical gas pressure on Fig. 9 corresponds in fact to $p_{v}$. We observe that the simulated curves exhibit a peak at the exact location of the drop of $h_{r}$, which also corresponds to the beginning of the front of $S_{l}$. It is difficult to verify whether the numerical peaks are realistically positioned, as the experimental data are not sufficient to characterise precisely the profiles on the entire thickness of the structure and then the existence and location of such peaks. Moreover, gas pressure measures do not appear to be very precise; in particular, the two close points situated at $r=0.027$ 


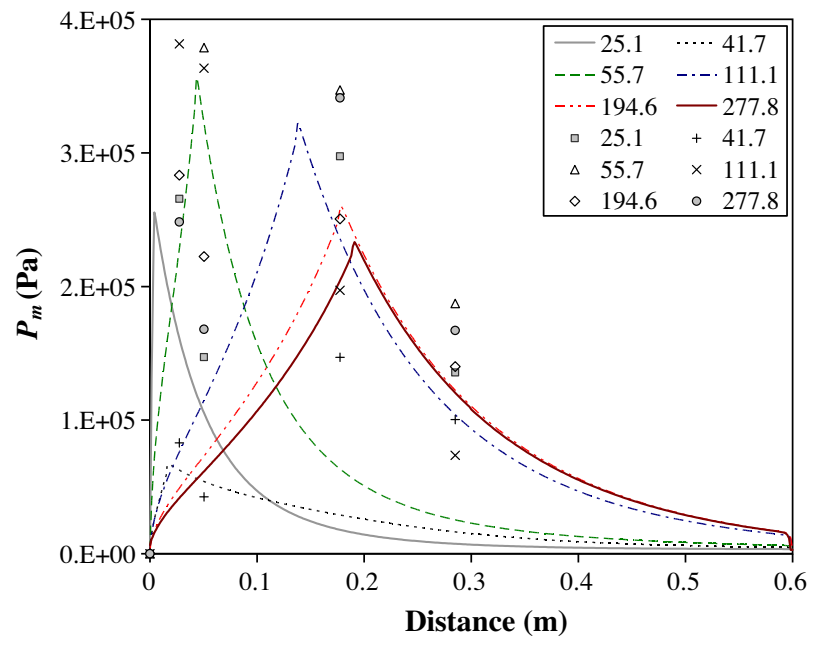

Fig. 9. Experimental (symbols, [12]) and numerical (lines) profiles of gas pressure $p_{m}$ as a function of the radial distance from the inner surface at different times (hours).

and $0.044 \mathrm{~m}$ exhibit quite important deviations which are to a certain extent questionable. The large sensor dimensions could be responsible for local perturbations in both gas and liquid phases, and for weakening of mechanical properties so that the sensor zone could be a privileged site for crack initiation.

Nevertheless, we observe that the simulations generally underestimate the experimental gas pressures. The discrepancies may exceed $1-2 \times 10^{5} \mathrm{~Pa}$ in the region near the heated surface, which is relatively high. Apart from the experimental uncertainties, these divergences may be due to the fact that the air phase is neglected in the model. It is worth noting that a recent paper [53] reports for conditions quite close to the ones studied here that the air pressure may reach values of about $2-2.5 \times 10^{5} \mathrm{~Pa}$, i.e. not far from the discrepancies observed. On the other hand, in [14] the values of air pressure for similar calculations rather range between 1$1.5 \times 10^{5} \mathrm{~Pa}$. These two results then tend to confirm the above hypothesis that the air phase may contribute to the gas pressure by an amount of $1-2 \times 10^{5} \mathrm{~Pa}$. Further investigations would however be necessary to completely elucidate this aspect, including simulations with a more sophisticated model taking into account the air phase.

The temporal evolutions of vertical and orthoradial strains at points located on the heated inner face in the middle plan and at $0.285 \mathrm{~m}$ of the middle plan of the structure are depicted on Fig. 10 up and down, respectively. The strains considered here are the total ones without the contribution of the thermal strains. Overall, the numerical results appear in reasonably good agreement with experimental ones ([12]). In particular, during the heating phase (i.e. up to about $60 \mathrm{~h}$ ) the simulated curves are quite close to the experiments. Some significant divergences become visible in the next stage, i.e. when the external loading temperature is constant and equal to $200^{\circ} \mathrm{C}$. In this phase and for the point located at the mid-plan (Fig. 10 up), magnitudes of both vertical and orthoradial numerical strains are overestimated by about $1-$ $1.5 \times 10^{-4}$, whereas for the point at $0.285 \mathrm{~m}$ from the mid-plan (Fig. 10 down) the magnitude of the simulated vertical strain is larger than the experimental one of around $2 \times 10^{-4}$, and the orthoradial strain is slightly underestimated.

The numerical crack patterns in the structure are depicted on Fig. 11 at different times. According to these results, the structure is subjected to a localized mechanical damage (macrocracks) caused by the temperature gradients. This cracking initiates at the beginning of the heating phase and at $27.8 \mathrm{~h}$ we observe 2
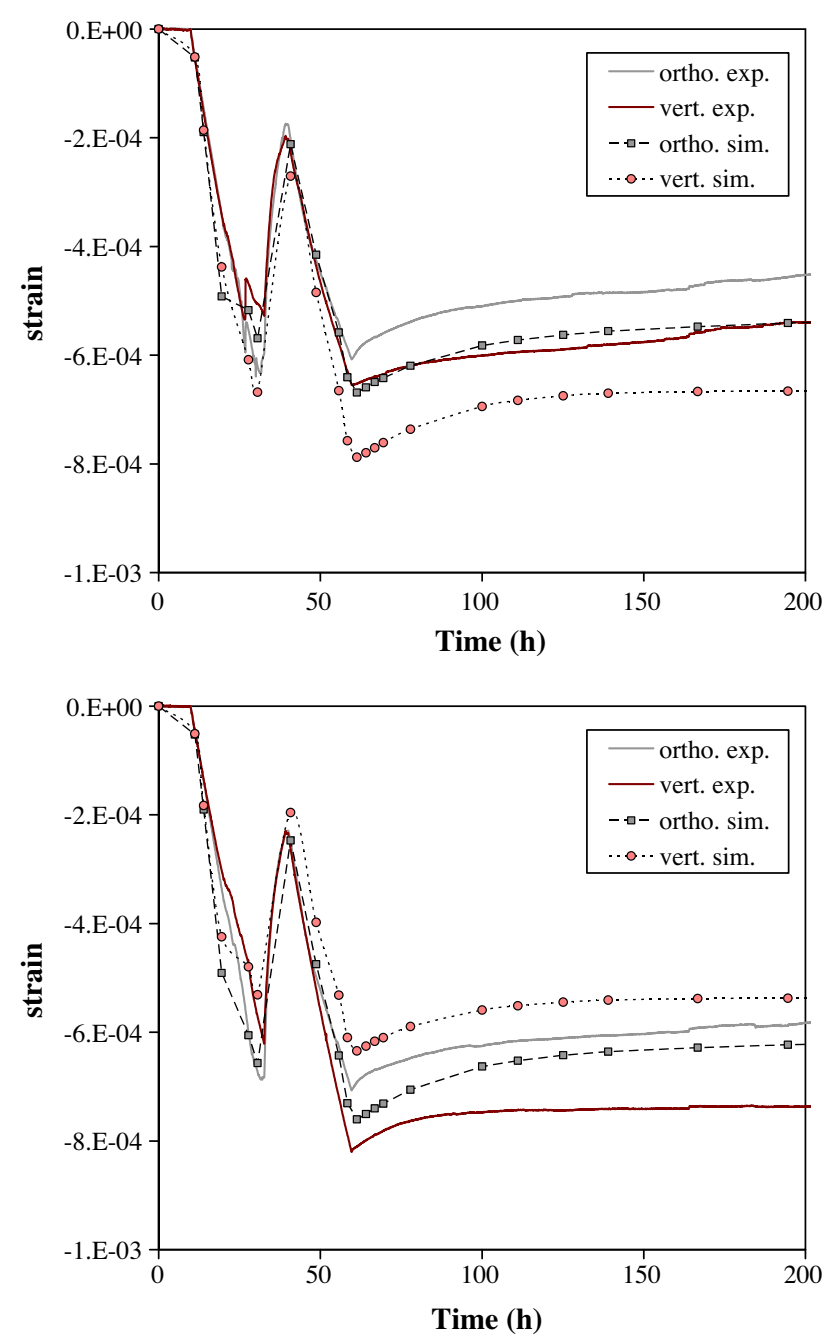

Fig. 10. Temporal evolution of numerical and experimental ([12]) vertical and orthoradial strains at the points situated on the internal (heated) face in the middle plan (up) and at $0.285 \mathrm{~m}$ of the middle plan (down) of the structure.

important cracking zones, one located in the mid-plan and along the neighbouring vertical steel rebars in the cold region, and the other appearing as a slightly inclined macrocrack situated in the upper part of the structure. For higher temperatures (i.e. for greater times), these damaged zones progress, in particular in the region of the reinforcement steels near the external surface. Besides, the circumferential rebars appear to promote damage in this region. We further observe that a damage zone initiates and propagates progressively in the colder zone near the upper surface for times greater than about $60 \mathrm{~h}$. However, it is difficult to validate and assess the suitability of these numerical damage patterns as no precise experimental data are available.

The Fig. 12 presents the distribution of vertical (left) and orthoradial (right) stresses denoted as $\sigma_{z z}$ and $\sigma_{\theta \theta}$, respectively, in the upper half of the structure at $250 \mathrm{~h}$. As expected, we observe that the inner part of MAQBETH on about $0.15 \mathrm{~m}$ of thickness is in a compressive state of stresses (up to $-13 \mathrm{MPa}$ by place for both of components $\sigma_{z z}$ and $\sigma_{\theta \theta}$ of the stress tensor) while the outer main part is slightly in tension. According to Fig. 12, the maximum tensile stresses reach about 3-3.5 MPa and are situated at the limit between the compression and tension zones. We also note that the region located in the upper part and near the inner surface of the structure is globally in tension. The position of the macrocracks as depicted on Fig. 11 is clearly visible, in particular on Fig. 12 left 


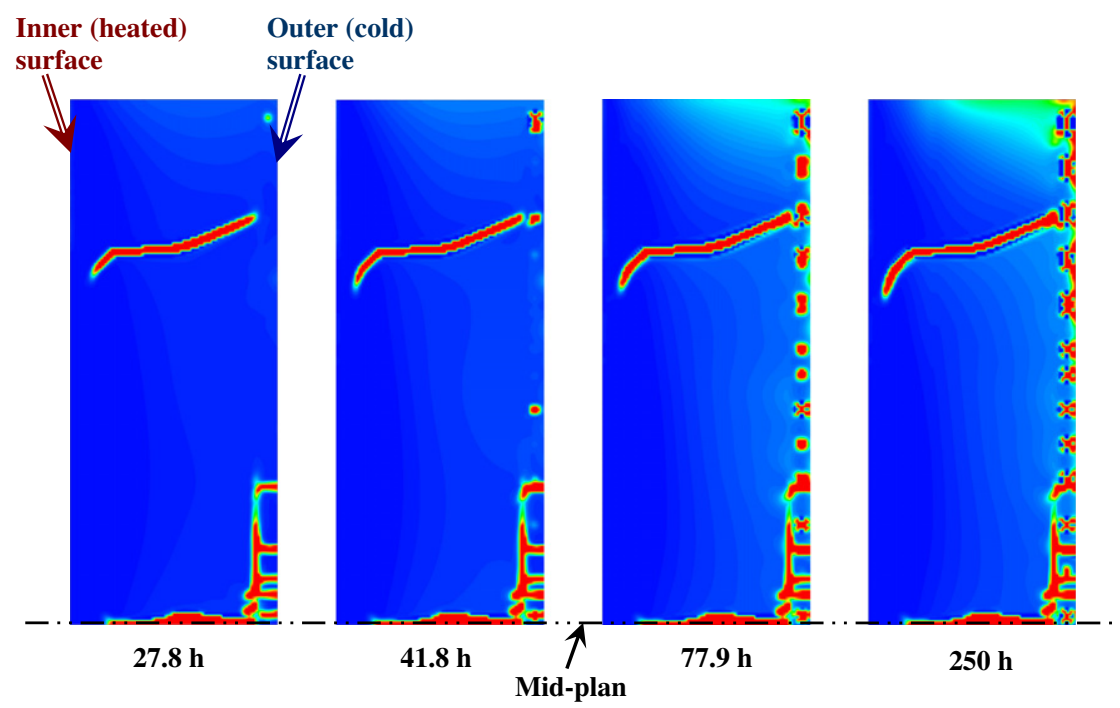

Fig. 11. Numerical damage patterns in the upper part of the structure at different times.

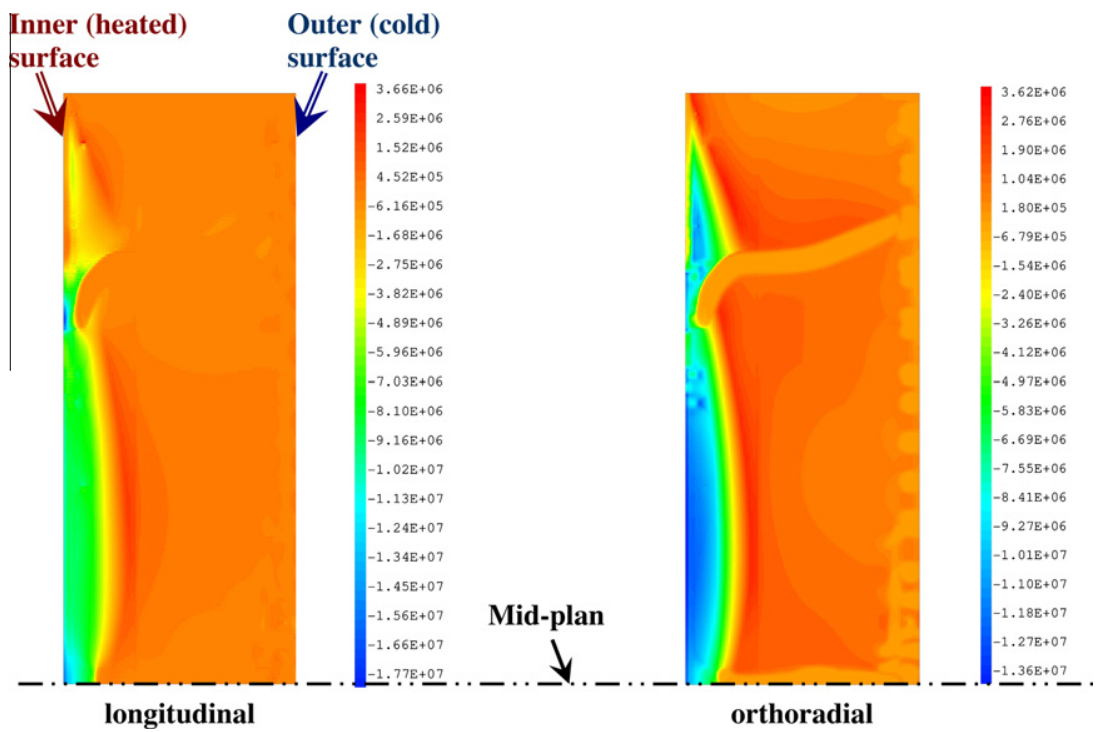

Fig. 12. Numerical longitudinal (left) and orthoradial (right) stress distribution in the upper part of the structure at $250 \mathrm{~h}$.

showing the orthoradial stress distribution. The numerical stress fields as obtained support the fact that the thermal loading inducing relatively important thermal gradients between the inner and outer surfaces (see Fig. 7) is mainly responsible for the mechanical response of the structure and then for the damage initiation and propagation. By contrast, the capillary pressure effects due to drying seem not to contribute significantly to this global state of stresses. Indeed, even in the most desaturated zones subjected to high capillary pressures (i.e. near the inner surface of the structure), the total stresses remain negative (compression) as a result of thermal dilation restrained by the colder (outer) part of the structure. In this situation, the role of capillary pressures appears then to lessen the compressive stresses due to the thermal loading.

To conclude, the model appears to relatively correctly reproduce the main features of the MAQBETH behaviour when subjected to thermal loading up to $200{ }^{\circ} \mathrm{C}$ with moderate heating rate, in terms of temperature, relative humidity, gas pressure and strains profiles. To evaluate the influence of the newly introduced temperature-dependant sorption curve on the results, additional computations were carried out by keeping unchanged the sorption curve at $20^{\circ} \mathrm{C}$ on the whole range of temperature. The corresponding results are analyzed and compared in terms of $h_{r}, S_{l}$ and $p_{m}$ profiles to the ones presented previously in the next section.

\subsection{Effects of the temperature-dependent sorption curves}

In this section are presented the results obtained with a temperature-independent sorption curve (the reference temperature adopted for this curve is $20^{\circ} \mathrm{C}$ ), while keeping the other data and parameters unchanged, with the notable exception of the liquid permeability $k_{m l}^{0}$. This parameter had indeed to be modified to conserve the same water mass loss (identified here as an indicator of the drying process) in the whole structure. In fact we observed that with the value of $k_{m l}^{0}=3 \times 10^{-22} \mathrm{~m}^{2}$ as retained for the simulations in Section 4.2 with the temperature-dependant sorption curves, the water migration within the structure was significantly lessened in the case of the constant sorption curve. We then increased $k_{m l}^{0}$ so as to obtain the same water mass loss at $250 \mathrm{~h}$ in the two cases. The value of $k_{m l}^{0}=6 \times 10^{-21} \mathrm{~m}^{2}$, i.e. multiplied by 20 , has been adopted to fulfil this condition. As a first result of this analysis, 
the simulations then indicate that the introduction of the temperature-dependency in the sorption curves as proposed in Section 3.2 tends to augment the water transfers, and consequently leads to a more important water mass loss. A detailed scrutiny of the results in terms of liquid pressure profiles (not shown here for conciseness) shows that the corresponding gradients, which are the main driving forces of the water migration in the model (see Eqs. (8) and (10)), are indeed higher in magnitude in the case of temperaturedependant sorption curves, especially in the vicinity of the inner heated surface of the structure.

Fig. 13 is the equivalent of the Fig. 8 and shows the numerical (lines) and experimental (symbols, [12]) radial profiles of $h_{r}$ (up), and numerical profiles of $S_{l}$ (down) obtained at mid-height of the structure at various times. We clearly observe radically different profiles from those of Fig. 8 for both quantities. The main distinction is the absence of drying front in the case of non evolving sorption curve. The shape of both $h_{r}$ and $S_{l}$ profiles appears smoother, indicating a more progressive desaturation of the structure: at $194.5 \mathrm{~h}$ the drying process affects almost all the structure thickness, whereas only the first $8 \mathrm{~cm}$ are subjected to a significant desaturation (i.e. $S_{l}<0.4$ ). On the opposite, in the case of temperature-dependant sorption curves (Fig. 8), about one third of the structure is affected by drying and undergoes an intense desaturation $\left(S_{l}<0.1\right)$. This observation also applies to a lesser extent in the region of the outer (cold) surface. Finally, we note that the agreement between the experimental data and the simulated $h_{r}$ profiles
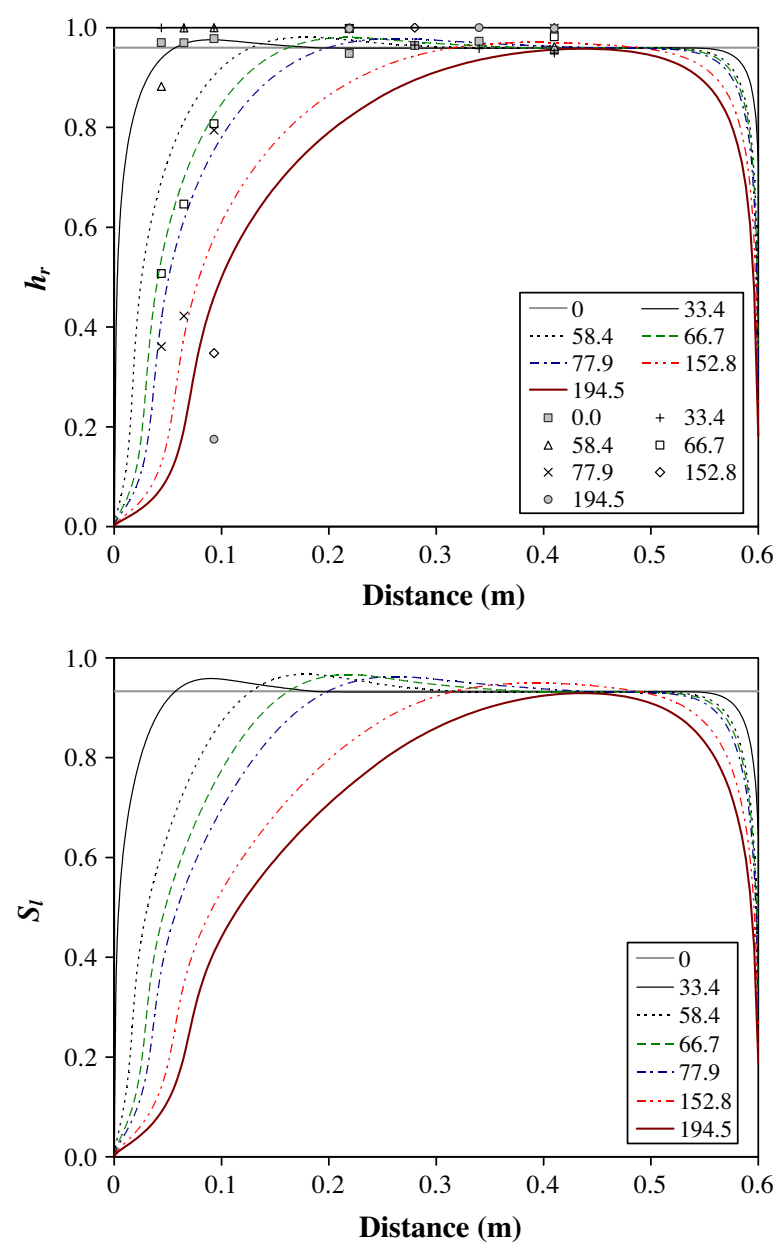

Fig. 13. Profiles of relative humidity $h_{r}$ (up) and liquid saturation $S_{l}$ (down) as a function of the radial distance from the inner surface at different times (hours). The experimental data of $h_{r}$ are presented in symbols [12], and the numerical results obtained with a temperature-independent sorption curve in lines. of Fig. 13 is less good than with the profiles of Fig. 8. In particular, the results with constant sorption curve are not able to reproduce the increase of the initial $h_{r}$ due to temperature elevation from about 0.96 to near 1 as measured experimentally. One should keep in mind that these considerations are based on results obtained with different liquid permeability in the two simulation cases. In particular, the reported lower gradients of saturation degree for the calculations with constant sorption curve also result from the 20 times greater value adopted for the liquid permeability $k_{m l}^{0}$. However, the simulations performed with the same value of $k_{m l}^{0}$ (not shown here) present the same trends as in Fig. 13, i.e. a less marked and more progressive drying front than the case with temperature-dependent sorption curve.

Fig. 14 presents the numerical (lines) and experimental (symbols, [12]) radial profiles of gas pressure obtained with a temperature-independent sorption curve at mid-plan of the structure for various times. This Figure is to be compared to Fig. 9 calculated with evolving sorption curves. Again, quite different profiles are simulated: in the case of Fig. 14 the peaks of pressure are closer to the inner surface due to a less significant desaturation in this zone. However the maximum pressure reached are slightly higher, which seems to better correspond to the experimental values. Moreover, similarly to the results of Fig. 13, the non-evolving sorption curve leads to softer gas pressure profiles than evolving ones, in particular in the vicinity of the peaks.

Finally, it is worth noting that the temperature profiles and the temporal evolutions of strains are only weakly affected by the temperature-dependency of the sorption curve, and for that reason the results obtained in the case of a constant curve are not reported here, as they are very similar to those of Figs. 7 and 10, respectively.

To summarize, it appears that taking into account the temperature effects on the sorption curves as defined in Section 3.2 leads to profiles of relative humidity and saturation degree within the structure significantly different from those obtained with a constant curve (corresponding to the one at $20^{\circ} \mathrm{C}$ ). The gas pressure profiles are also affected, but to a lesser extent. An important point is that the drying process appears much slower in the case of constant sorption curve, and the permeability to liquid has to by multiplied by 20 to obtain a water mass loss comparable to that calculated with temperature-dependant sorption curves. Also, desaturation due to drying takes place globally more progressively in the former case, while this process occurs with a very marked front with evolving curves. This front is the direct consequence

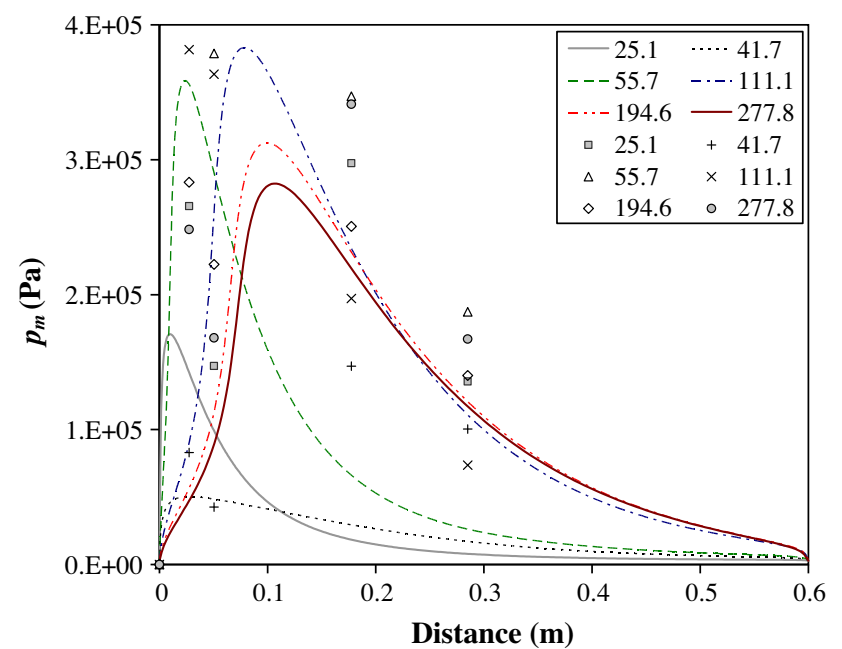

Fig. 14. Experimental (symbols, [12]) and numerical (lines, obtained with a temperature-independent sorption curve) profiles of gas pressure $p_{m}$ as a function of the radial distance from the inner surface at different times (hours). 
of the abrupt variation of the modelled sorption curves near $h_{r}=1$ for high temperatures. Overall, the results with temperaturedependant sorption curves are closer to the experimental data than with constant one. However, the consequence of the desaturation front is that the numerical convergence of the mass conservation equation for water is more difficult. Accordingly, a finer mesh and smaller time steps are needed in general to achieve this convergence satisfactorily. In the simulations presented in this subsection, the computation time is about two times lower than for the simulations with temperature-dependant sorption curves.

\section{Conclusions}

This work presents numerical results regarding the behaviour of an annular reinforced concrete structure submitted to heating up to $200{ }^{\circ} \mathrm{C}$ (MAQBETH). The simulations are carried out by means of a simplified coupled THM model developed previously [1] and based on the mechanics of partially saturated porous media. In this study, this THM model is improved by accounting for the temperature effects in the water retention curves, which are introduced by making use of the isosteric heat of sorption. Moreover, numerical strategies for including in the simulations the steel reinforcement rebars and two different meshes for solving the $\mathrm{TH}$ and mechanical problems are implemented. The results obtained are compared with experimental data in terms of profiles of temperature, gas pressure, relative humidity and strains in the median plan of the structure as a function of time. This comparison shows in general a reasonable agreement. In particular, the model is able to precisely estimate the temperature evolutions in the structure.

Not surprisingly, we observe that the temperature-dependent sorption curves affect significantly the relative humidities and saturation degrees, and to a lesser extent the gas pressures. Quite different shape of $h_{r}$ and $S_{l}$ profiles within the structure are obtained for the two cases of evolving and constant (i.e. equal to the one at $20^{\circ} \mathrm{C}$ ) sorption curves. In particular, we note that the drying process occurs with a very marked front in the first case while desaturation of the structure takes place much more progressively in the second. This front causes numerical convergence difficulties, which necessitate to refining the mesh and reducing the time steps. The computation time is then higher when the sorption curves evolve with temperature. Interestingly, the simulations indicate that keeping the sorption curve unchanged, as is commonly adopted in many THM model for simplicity, leads to a much slower overall drying, so that the liquid permeability has to be significantly increased to obtain a water mass loss similar to the case of temperature-dependant curves. By contrast, the strains evolutions and temperature profiles do not appear to be notably affected by the different sorption curves. Finally, the simulations prove that a precise description of the hydric state and of the water flux in a structure subjected to $\mathrm{TH}$ loadings requires necessarily taking into account the dependence upon temperature in the modelling of the sorption curves.

\section{Acknowledgment}

Special thanks are due to EDF and CEA for their financial support.

\section{References}

[1] Bary B, Durand S, Ranc G, Carpentier O. A coupled thermo-hydro-mechanical model for concrete subjected to moderate temperatures. Int J Heat Mass Transfer 2008;51:2847-62.

[2] Lewis R, Schrefler BA. The finite element method in the static and dynamic deformation and consolidation of porous media. New York: John Wiley \& Sons; 1998.
[3] Gawin D, Pesavento F, Schrefler BA. Modelling of hygro-thermal behaviour of concrete at high temperature with thermo-chemical and mechanical material degradation. Comput Meth Appl Mech Eng 2003;192:1731-71.

[4] Coussy O. Poromechanics. New York: John Wiley \& Sons; 2004.

[5] Khalili N, Loret B. An elasto-plastic model for non-isothermal analysis of flow and deformation in unsaturated porous media: formulation. Int J Solids Struct 2001;38:8305-30.

[6] Dal Pont S, Ehrlacher A. Numerical and experimental analysis of chemical dehydration, heat and mass transfers in a concrete hollow cylinder submitted to high temperatures. Int J Heat Mass Transfer 2004;47:135-47.

[7] Mounajed G, Obeid W. A new coupling FE model for the simulation of thermalhydro-mechanical behaviour of concretes at high temperatures. Mater Struct 2004;37:422-32.

[8] Davie CT, Pearce CJ, Bicanic N. A fully generalised, coupled, multi-phase, hygrothermo-mechanical model for concrete. Mater Struct 2010;43:13-33.

[9] Bazant ZP, Cusatis G, Cedolin L. Temperature effect on concrete creep modeled by microprestress-solidification theory. J Eng Mech 2004;130:691-9.

[10] Poyet S, Charles S. Temperature dependence of the sorption isotherms of cement-based materials: heat of sorption and Clausius-Clapeyron formula. Cem Concr Res 2009;39:1060-7.

[11] Ishida T, Maekawa K, Kishi T. Enhanced modeling of moisture equilibrium and transport in cementitious materials under arbitrary temperature and relative humidity history. Cem Concr Res 2007;37:565-78.

[12] Ranc G, Sercombe J, Rodrigues S. Comportement à haute température du béton de structure - impact de la fissuration sur les transferts hydriques (in french). Revue Francaise de Génie Civil 2003;7:397-424.

[13] Ranc G, Gallé C, Sercombe J, Pin M, Rodrigues S, Durand S. Bilan synthétique des actions de R\& D sur le comportement thermo-hydro-mécanique du béton réalisées au LECBA sur la période 1999-2003 (in french). CEA Internal Report; 2003.

[14] de Morais MVG, Bary B, Ranc G, Dal Pont S, Durand S. Comparative analysis of coupled thermo-hydro-mechanical models for concrete exposed to moderate temperatures. Numer Heat Transfer, A: Appl 2009;55:654-82.

[15] Gawin D, Majorana CE, Schrefler BA. Numerical analysis of hygro-thermal behaviour and damage of concrete at high temperature. Mech Cohes-Frict Mater 1999;4:37-74.

[16] Bary B. Estimation of poromechanical and thermal conductivity properties of unsaturated isotropically microcracked cement pastes. Int J Numer Anal Meth Geomech 2011;35:1560-86.

[17] Kalifa P, Menneteau FD, Quenard D. Spalling and pore pressure in HPC at high temperatures. Cem Concr Res 2000;30:1915-27.

[18] Budiansky B, O'Connell RJ. Elastic moduli of a cracked solid. Int J Solids Struct 1976;12:81-97.

[19] Zheng QS, Du DX. An explicit and universally applicable estimate for the effective properties of multiphase composites which accounts for inclusion distribution. J Mech Phys Solids 2001;49:2765-88.

[20] Mazars J. Description of micro- and macroscale damage of concrete structures. Eng Fract Mech 1985;25:729-37.

[21] Pijaudier-Cabot G, Bazant ZP. Non local damage theory. J Eng Mech 1987;113:1512-33.

[22] Khoury GA. Strain of heated concrete during two thermal cycles. Part 1: strain over two cycles, during first heating and at subsequent constant temperature. Mag Concr Res 2006;58:367-85.

[23] Dvorak GJ. Transformation field analysis of inelastic composite materials. Proc R Soc A 1992;437:311-27.

[24] Dormieux L, Kondo D, Ulm FJ. Microporomechanics. Chichester: John Wiley \& Sons; 2006.

[25] Xi YP, Jennings HM. Shrinkage of cement paste and concrete modelled by a multiscale effective homogeneous theory. Mater Struct 1997;30:329-39.

[26] Bernard O, Ulm FJ, Lemarchand E. A multiscale micromechanics-hydration model for the early-age elastic properties of cement-based materials. Cem Concr Res 2003;33:1293-309.

[27] Dormieux L, Lemarchand E, Kondo D, Fairbairn E. Elements of poromicromechanics applied to concrete. Mater Struct 2004;37:31-42.

[28] Ulm FJ, Constantinides G, Heukamp FH. Is concrete a poromechanics material? - A multiscale investigation of poroelastic properties. Mater Struct 2004;37:43-58.

[29] Sanahuja J, Dormieux L, Chanvillard G. Modelling elasticity of a hydrating cement paste. Cem Concr Res 2007;37:1427-39.

[30] Stora E, Bary B, He QC, Deville E, Montarnal P. Modelling and simulations of the chemo-mechanical behaviour of leached cement-based materials: interactions between damage and leaching. Cem Concr Res 2010;40:1226-36.

[31] Pichler B, Hellmich C, Eberhardsteiner J. Spherical and acicular representation of hydrates in a micromechanical model for cement paste: prediction of earlyage elasticity and strength. Acta Mechanica 2009;203:137-62.

[32] Mainguy M, Coussy O, Boroghel-Bouny V. Role of air pressure in drying of weakly permeable materials. J Eng Mech 2001;127:582-92.

[33] McLachlan DS. An equation for the conductivity of binary mixtures with anisotropic grain structures. J Phys C: Solid State Phys 1987;20:865-77.

[34] van Genuchten MT. Closed-form equation for predicting the hydraulic conductivity of unsaturated soils. Soil Sci Soc Am J 1980;44:892-8.

[35] Monlouis-Bonnaire JP, Verdier J, Perrin B. Prediction of the relative permeability to gas flow of cement-based materials. Cem Concr Res 2004;34:737-44.

[36] Bazant ZP, Kaplan M. Concrete at high temperatures. Material properties and mathematical models. Harlow: Longman Group; 1996. 
[37] Ulm FJ, Coussy O, Bazant ZP. The "Chunnel" fire. I: Chemoplastic softening in rapidly heated concrete. J Eng Mech 1999;125:272-82.

[38] Hundt J, Kantelberg H. Sorptionsuntersuchungen an Zemestein, Zementmörtel und Beton (in german). Deutscher Ausschuss für Stahlbeton 1978; Heft 297:25-39.

[39] Daïan J-F. Processus de condensation et de transfert d'eau dans un matériau méso et macroporeux - Etude expérimentale du mortier de ciment (in french) [Ph.D. Thesis]: Institut National Polytechnique de Grenoble (INPG); 1986.

[40] Daïan J-F. Condensation and isothermal water transfer in cement mortar. Part I:- Pore size distribution, equilibrium, water condensation and imbibition. Transport Porous Media 1988;3:563-89.

[41] Daian J-F. Condensation and isothermal water transfer in cement mortar. Part II: Transient condensation of water vapor. Transport Porous Media 1989;4:1-16.

[42] Radjy F, Sellevold EJ, Hansen KK. Isosteric vapor pressure-temperature data for water sorption in hardened cement paste: enthalpy, entropy and sorption isotherms at different temperatures. Report BYG-DTU R057: Technical University of Denmark (DTU), Lyngby, Denmark; 2003. p. 58.

[43] Poyet S. Experimental investigation of the effect of temperature on the first desorption isotherm of concrete. Cem Concr Res 2009;39:1052-9.

[44] Atkins P, de Paula J. Atkin's physical chemistry. 8th ed. Oxford, United Kingdom: Oxford University Press; 2006.

[45] Anderson RB. Modifications of the Brunauer, Emmett and Teller equation. J Am Chem Soc 1946;68:686-91.
[46] Brunauer S, Skalny J, Bodor EE. Adsorption on non porous solids. J Colloid Interface Sci 1969;30:546-52.

[47] Bazant ZP, Thonguthai W. Pore pressure and drying of concrete at hightemperature. J Eng Mech 1978;104:1059-79.

[48] Bazant ZP, Thonguthai W. Pore pressure in heated concrete walls - theoretical prediction. Mag Concr Res 1979;31:67-76.

[49] Pearce CJ, Kukla K, Bicanic N, Davie CT. Modelling of transport processes in concrete at elevated temperatures - an alternative formulation for sorption isotherms. Proceedings of EURO-C. Mayrhofen im Zillertal, Austria; 2006. p. 623-32.

[50] Cast3M. Finite Element code developed at CEA. <http://www-cast3m.cea.fr>.

[51] Gallé C, Sercombe J. Permeability and pore structure evolution of silicocalcareous and hematite high-strength concretes submitted to high temperatures. Mater Struct 2001;34:619-28.

[52] Sercombe J, Gallé C, Ranc G. Modélisation du comportement du béton à haute température: transferts de fluides et de chaleur et déformations pendant des transitoires thermiques; 2001.

[53] Gawin D, Pesavento F, Schrefler BA. What physical phenomena can be neglected when modelling concrete at high temperature? A comparative study. Part 2: Comparison between models. Int J Solids Struct 2011;48:1945-61.

[54] Ranznjevic K. Tables et diagrammes thermodynamiques: Eyrolles; 1970

[55] ASHRAE. Handbook of fundamentals: ASHRAE; 1993.

[56] Pezzani P. Propriétés thermodynamiques de l'eau. Techniques de l'Ingénieur; 1988. 